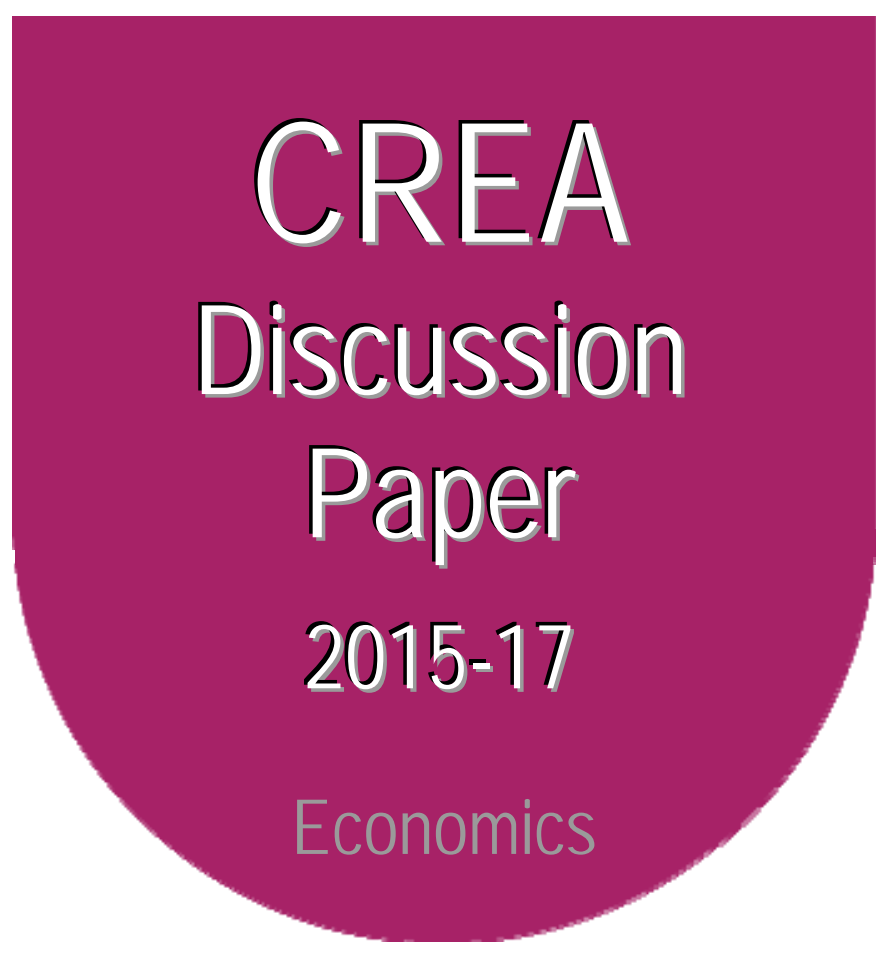

Center for Research in Economics and Management University of Luxembourg

\title{
Carbon tax, pollution and spatial location of heterogeneous firms
}

available online : http://wwwfr.uni.Iu/recherche/fdef/crea/publications2/discussion_papers

Nelly Exbrayat, Jean Monnet University, IAE, Saint-Etienne Stéphane Riou, Jean Monnet University, IAE, Saint-Etienne Skerdilajda Zanaj, CREA, Université du Luxembourg

November, 2015

For editorial correspondence, please contact: crea@uni.lu

University of Luxembourg

Faculty of Law, Economics and Finance 162A, avenue de la Faïencerie L-1511 Luxembourg 


\title{
Carbon tax, pollution and spatial location of heterogeneous firms*
}

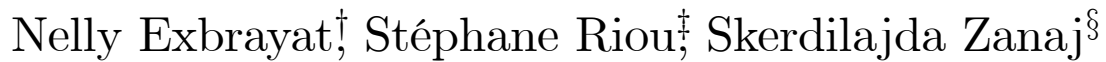

November 20, 2015

\begin{abstract}
In this paper, we investigate the effects of a global carbon tax and its ability to curb carbon emissions in a two-country setup characterized by an uneven spatial distribution of mobile heterogeneous firms. Trade takes place between the two asymmetric countries and carbon dioxide $\left(\mathrm{CO}_{2}\right)$ emissions are a by-product of the production activity of manufacturing firms. We advance the hypothesis that although a global carbon tax is an attractive environmental measure, it may be subject to debate because, among other effects, it can have a significant impact on the location of heterogeneous firms as well as on foreign trade patterns worldwide.
\end{abstract}

Keywords: global carbon tax; spatial selection; heterogeneous firms

JEL classification: F12; F15; H22; H87; Q28

${ }^{*}$ We are grateful for discussions and comments to Pierre Picard, Maria Eugenia Sanin, Ingmar Schumacher, Cecilia Vergari and Cees Withagen, as well as participants at the International Workshop On Natural Resources, Environment, Urban Economics, International Trade and Industrial Organisation, in St. Petersburg, Russia, October 2013, at the 2015 PET conference in Luxembourg, and at the Game Theory and Applications in Lisbon, November, 2015. The usual disclaimer applies.

†Université de Lyon, Lyon, F-69003, France; Université Jean Monnet; CNRS, GATE Lyon St Etienne, Saint-Etienne, F-42000, France. email: nelly.exbrayat@univ-st-etienne.fr

${ }^{\ddagger}$ Université de Lyon, Lyon, F-69003, France; Université Jean Monnet; CNRS, GATE Lyon St Etienne, Saint-Etienne, F-42000, France. email: stephane.riou@univ-st-etienne.fr

§Corresponding author: CREA, University of Luxembourg, Avenue de la Faïencerie, 162A, L-1511, Luxembourg. email: skerdilajda.zanaj@uni.lu 


\section{Introduction}

Despite the growing number of policies aimed at reducing global warming, emissions grew more quickly between 2000 and 2010 than in any of the three previous decades (IPCC's Fifth Assessment Report, 2014). Annual greenhouse gas emissions have increased by precisely one gigatonne equivalent of dioxide carbon $\mathrm{CO}_{2}(2.2 \%)$ over the past decade alone. ${ }^{1}$ Such an increase in pollution poses the threat of a catastrophic increase in global temperatures, triggering strong reactions from, among others, several economists.

In fact, G. Mankiw, W. Nordhaus, J. Stiglitz and others have recently argued that a global -harmonized- carbon tax should be applied. A first argument is summarized by Mankiw (N-Y. Times, October 16th, 2007) as follows:

"The scientists tell us that world temperatures are rising because humans are emitting carbon into the atmosphere. Basic economics tells us that when you tax something, you normally get less of it. So if we want to reduce global emissions of carbon, we need a global carbon tax. Q.E.D."

In other words, a global carbon tax would be an ideal instrument because it would address both domestic and transboundary pollution. The second main argument refers to the wellknown carbon leakage issue. In a globalized world, production activities can shift to countries with laxer environmental policies such that decentralized environmental policies are less effective in reducing emissions. Hence, a global carbon tax is desirable because it would be neutral with respect to any delocalization strategy of firms.

In this paper, we investigate the effects of a global carbon tax and its ability to curb carbon emissions in a globalized economy characterized by an uneven spatial distribution of heterogeneous firms. Our results challenge the claim that a global carbon tax could succeed in improving the quality of environment without raising competitiveness concerns. Indeed, we argue that although a global carbon tax is an attractive environmental measure, it may be subject to debate because, among other effects, it can have a significant impact on the location of (heterogeneous) firms as well as on foreign trade patterns worldwide. We evaluate these effects by

\footnotetext{
${ }^{1}$ In comparison, greenhouse gas emissions grew on average by 0.4 gigatonne equivalent of $\mathrm{CO}_{2}$ per year $(1.3 \%)$ from 1970 to 2000. The last IPCC report also states that half of cumulative anthropogenic $\mathrm{CO}_{2}$ emissions between 1750 and 2010 have occurred within the last 40 years.
} 
investigating the introduction of a global carbon tax on emissions in the context of a globalized economy characterized by international trade and firm mobility. We build a trade model with asymmetric countries, heterogeneous and mobile firms inspired by Okubo et al. (2010). Carbon dioxide $\left(\mathrm{CO}_{2}\right)$ emissions are a byproduct of the production activity of manufacturing firms, which we assume export part of their production. Therefore, our model accounts for the fact that $\mathrm{CO}_{2}$ emissions, embodied in international trade, are an important contributing factor of the increase in emissions, especially in countries such as China (Ahmad and Wyckoff, 2003; Peters and Hertwich, 2008; Weber et al., 2008; Lin and Sun, 2010). ${ }^{2}$ Moreover, manufacturing firms are assumed to be either clean or dirty depending on the technology they adopt, with each technology associated with a specific level of production cost. It follows that a global carbon tax policy affects the location choices of clean and dirty firms in different ways. This framework allows for the analysis of the location decision of dirty and clean firms, the effect of a carbon tax on trade patterns and, finally, the efficiency of a global carbon tax in reducing global emissions. To focus on this subject, we abstract from all the political-economic factors that make a global carbon tax a public policy difficult to implement.

By characterizing the location equilibria of heterogeneous firms according to the level of trade costs, we first show that trade liberalization leads to more agglomeration in the larger country, which in turn raises global emissions. Thus, the need for a global carbon tax is becoming higher as trade costs fall. Nevertheless, when different market sizes and increasing returns to scale are considered, a carbon tax, even a global one, is not a spatially neutral policy instrument. We show that the implementation of a global carbon tax might have unexpected effects on environmental quality because of the relocation effects it generates. Specifically, a sufficiently low level of carbon has only positive effects for the environment; it lowers pollution emissions in any equilibrium spatial configurations and induces spatial relocations that are less harmful for the environment. Furthermore, we show that there exists a threshold value of the carbon tax above which trade patterns are considerably affected; in fact, firms cease to trade in the foreign country. Importantly, we show that this situation is a dark side of the effects of a global carbon tax because such a no-trade effect may lead to the disappearance of the most environmentally friendly configurations.

Our contribution first relates to the literature on the pollution haven hypothesis, according

\footnotetext{
${ }^{2}$ Such analysis builds on the distinction between emissions based on consumption and those based on production (Peters, 2008).
} 
to which pollution-intensive industries would move to countries with less stringent environmental regulation. Previous contributions generalize the model of reciprocal dumping by endogenizing the number of plants and their location (Markusen et al., 1993). Firms can react to a tightening of environmental policies by shutting down the plant and transferring production to plants in another country ${ }^{3}$. As a consequence, the decentralization of the environmental policy leads government to behave non-cooperatively. Depending on the level of disutility associated with pollution, government either chooses a strategy of environmental dumping or a strategy of the type "Not In My Back Yard" (Markusen and al., 1995). Zeng and Zhao (2009) develop a model in which manufacturing production generates cross-border pollution and location choices are driven by international differences in both environmental policy and agglomeration forces. ${ }^{4}$ The authors demonstrate that these manufacturing agglomeration forces alleviate the benefits of locating in a pollution haven. ${ }^{5}$ We contribute to this literature by analyzing whether the centralization of environmental policy through a global carbon tax does avoid relocation effects and further analyzing the ability of the tax to improve environmental quality.

This paper also contributes to the broad literature on the environmental impact of trade liberalization. Since the work of Grossman and Krueger (1993), it has become well known that trade liberalization can affect the environment through different channels. The question whether the overall impact will be positive or negative has given rise to many theoretical and empirical contributions (Sturm, 2003). Antweiler, Copeland and Taylor (2001) consider pollution as a public bad and they develop a Ricardian model allowing both for income and factor endowment differences across countries ${ }^{6}$. Their empirical results indicate that the overall impact of trade on environmental quality is positive but small. In our paper, we complement this literature by showing how trade liberalization influences the environment through firms' relocation strategies (rather than through technological-upgrading behavior) in an imperfectly competitive economy. Specifically, we show that the level of trade costs influences both the level

\footnotetext{
${ }^{3}$ Taking into account the fixed cost to set up a plant, Motta and Thisse (1994) demonstrate that such a relocation is less likely to occur.

${ }^{4}$ Agglomeration forces stem from the assumptions of increasing returns to scale and asymmetric market sizes.

${ }^{5}$ Empirical evidence related to the pollution haven hypothesis is also mixed (Ederington et al., 2005; Jeppesen et al. 2002; Eskeland and Harrison, 2003). Interestingly, Levinson and Taylor (2008) raise several methodological issues that help explain why empirical studies have difficulties in demonstrating the existence of this effect.

${ }^{6}$ Therefore, the influence of differences in factor endowment can dominate the impact of differences in environmental policy on comparative advantage.
} 
of global emissions in the absence of a carbon tax and the ability of such a policy instrument to improve environmental quality. Importantly, our theoretical contribution also allows for the analysis of how global environmental measures affect international trade patterns. We isolate a novel effect of the carbon tax on trade patterns that is not due to regulation externalities among countries competing for FDIs or capital.

The remainder of the paper is organized as follows. In section 2, we develop a model of trade with firms that differs with respect to firms' marginal cost and emission intensity and describe the outcome in the short run, when firms are immobile. In section 3, we describe the location choice made by firms in the long run, when clean firms bear a higher net marginal cost. In section 4, we analyze the ability of the global carbon tax to reduce global emissions. Finally, we explore the efficiency of the carbon tax when it is set at such a high level that dirty firms suffer a higher net marginal cost. The final section concludes the paper.

\section{The model}

We consider an economy with two countries $(i=H ; F)$, two production factors (labor $l$ and physical capital $n$ ) and two sectors in which firms produce two homogeneous goods: i) an industrial good $x$ with a polluting technology and ii) a numéraire good $z$ whose production does not yield carbon emissions. Country $H$ is supposed to host a share $\lambda>1 / 2$ of total population $l$, and each individual is equally endowed with one unit of labor and $n / l$ unit of capital. Residents work and consume in the country they live in but invest their capital in the country producing the highest return. Finally, we assume a supranational authority that implements a global carbon tax $t$ on per-unit carbon emissions.

\subsection{Preferences}

For analytical tractability, we assume that workers share the same quasi-linear utility function $u_{i}$ with respect to the numéraire $z$ and the manufactured good $x$, both goods being homogeneous. ${ }^{7}$ This assumption also allows for a focus on the role played by the technology. A consumer residing in country $i$ thus solves the following problem:

\footnotetext{
${ }^{7}$ Although the income effect is erased with quasi-linear utility, Dinopoulos et al. (2007, p.22), show that this type of preference behaves reasonably well in models of international trade.
} 


$$
\begin{aligned}
\operatorname{Max}_{x_{i}} u_{i} & \equiv\left(a-\frac{\beta x_{i}}{2}\right) x_{i}-\gamma E+z_{i} \\
\text { s.t. } \quad w_{i}+\bar{z}+r \frac{n}{l} & =x_{i} p_{i}+z_{i}
\end{aligned}
$$

where $a>0, x_{i}$ is the individual consumption level of the manufactured good, $z_{i}$ is the individual consumption of the numéraire, $\bar{z}$ is the individual endowment in the numéraire, $w_{i}$ the national wage rate, and $r$ the world net return rate to capital. We assume that the initial endowment $\bar{z}$ is large enough for the individual consumption of the numéraire to be strictly positive at the market outcome. Finally, $\gamma$ captures the individual damage arising from the total emissions of the manufacturing sector $(\mathbf{E})$, which are assumed to spill over across the two countries.

Given (1) and (2), the individual demand $x_{i}$ for the manufactured good is given by

$$
x_{i}=\frac{a-p_{i}}{\beta}, \quad \forall i=H, F
$$

\subsection{Technology and market structure}

Good $z$ is produced under constant returns to scale and perfect competition. Specifically, one unit of labor is required to produce one unit of output. Moreover, this good is costlessly traded and considered as the numéraire. Thus, its price as well as the individual wage rate are equal to one in each country as soon as this sector is active in both countries, i.e., $w_{i}=1, i=H, F$.

By contrast, good $x$ is produced under increasing returns to scale and yields carbon emissions that differ across firms. We consider two types of firms in particular, clean $(c)$ and dirty $(d)$, whose per-unit levels of carbon emission are given by $\varepsilon_{k}$ with $k=c, d$. Pollution is considered a global public bad. In other words, the utility loss induced by one unit of emissions from country $i$ is the same wherever individuals are located. Indeed, $\mathrm{CO}_{2}$ emissions are considered a global problem that justifies an internationally coordinated mitigation policy such as a global carbon tax.

Each type of firm requires one unit of capital to produce any amount of good $x$. The marginal requirement in labor can be viewed as a pollution abatement cost that varies across firms. There is a share $\mu$ of dirty firms whose marginal requirement in labor is normalized to zero (because they do not abate pollution) and whose per-unit emission level is given by $\varepsilon_{d}$. By contrast, the remaining $1-\mu$ share of firms are clean and pollute less, $\varepsilon_{c}<\varepsilon_{d}$, because of their 
marginal requirement of $m>0$ units of labor. Abatement costs usually quantify different types of expenditures for pollution abatement. They may involve design costs for a new process of production but also managerial effort for the required paperwork. In our paper, for simplicity, we assume a fixed amount of capital in each firm, but the abatement may change the intensity of use of this unit of capital per unit of labor, ultimately changing the labor requirement for each unit of good $x$ produced.

Finally, we consider that the manufactured good is costly traded. Each firm incurs a trade cost of $\tau>0$ units of the numéraire per unit of good $x$ shipped between the two countries.

\subsection{Short-run equilibrium}

In the short-run equilibrium, the location of each type of firm in each country is given. There are $n_{h}$ firms located in country $H$, and the rest, $n-n_{h}$, are located in $F$. Labor, capital and goods markets are cleared. Firms in the manufacturing sector produce under Cournot competition. Product markets are segmented because of trade costs (as in Brander and Krugman, 1983); that is, each firm determines a specific quantity to trade to the country in which its product is sold. Thus, the net profits of a $k$-type firm $(k=c, d)$ located in country $i$ selling its good in country $i$ and country $j$, are given by

$$
\begin{aligned}
\pi_{i}^{c} & =\left(p_{i}-m-t \varepsilon_{c}\right) x_{i i}^{c}+\left(p_{j}-m-t \varepsilon_{c}-\tau\right) x_{i j}^{c}-r_{i} \\
\pi_{i}^{d} & =\left(p_{i}-t \varepsilon_{d}\right) x_{i i}^{d}+\left(p_{j}-t \varepsilon_{d}-\tau\right) x_{i j}^{d}-r_{i}
\end{aligned}
$$

where $x_{i i}^{k}$ is the quantity the firm supplies to domestic consumers and $x_{i j}^{k}$ is the quantity it sells to foreign consumers. Moreover, $r_{i}$ is the rental rate of capital in country $i$, which is equalized across countries due to capital mobility $r_{H}=r_{F}=r$. The first-order condition for clean firms yields the following output choices:

$$
x_{h h}^{c}=\frac{\lambda l}{\beta}\left(p_{h}-m-t \varepsilon_{c}\right) \text { and } x_{h f}^{c}=\frac{(1-\lambda) l}{\beta}\left(p_{f}-m-t \varepsilon_{c}-\tau\right)
$$

for a firm located in country $\mathrm{H}$, and

$$
x_{f f}^{c}=\frac{(1-\lambda) l}{\beta}\left(p_{f}-m-t \varepsilon_{c}\right) \text { and } x_{f h}^{c}=\frac{\lambda l}{\beta}\left(p_{h}-m-t \varepsilon_{c}-\tau\right)
$$


for a firm located in country F. Mirror expressions hold for dirty firms, $m$ being replaced by 0 and $\varepsilon_{c}$ by $\varepsilon_{d}$. Solving the market-clearing condition for each country, we obtain the equilibrium prices $p_{i}$ in the short run:

$$
p_{i}=\frac{a+n_{j} \tau+n \omega}{n+1}, i, j=h, f
$$

where $\omega=(1-\mu)\left(m+t \varepsilon_{c}\right)+\mu t \varepsilon_{d}$ represents the average marginal cost after taxation. The difference in prices is $p_{h}-p_{f}=\tau\left(n_{f}-n_{h}\right) /(n+1)$.

Before describing the equilibrium output, some comments are in order. First, the price level in a country decreases with the number of firms located in the country as competition becomes fiercer. Second, the distribution of firms between the two technologies modulates the price level through its effect on the average marginal cost. Indeed, we have

$$
\frac{\partial p_{i}}{\partial \mu}=\frac{n}{n+1}\left(t\left(\varepsilon_{d}-\varepsilon_{c}\right)-m\right) .
$$

Intuitively, the price level increases with the share of clean firms $\left(\partial p_{i} / \partial \mu<0\right)$ in the economy as long as their marginal cost is higher than the marginal cost of dirty firms. Although this is always the case in the absence of carbon tax $t$, the reverse may hold when the supranational authority determines its implementation. More precisely, $\partial p_{i} / \partial \mu>0$ holds if and only if

$$
t>\bar{t} \equiv \frac{m}{\varepsilon_{d}-\varepsilon_{c}}
$$

Third, we observe that the implementation of a positive carbon tax yields higher prices:

$$
\frac{\partial p_{i}}{\partial t}=\frac{n}{n+1}\left((1-\mu) \varepsilon_{c}+\mu \varepsilon_{d}\right)>0, i=h, f .
$$

This tax incidence effect is proportional to the average emission intensity $(1-\mu) \varepsilon_{c}+\mu \varepsilon_{d}$. In particular, the incidence of the carbon tax will be strong when the manufacturing sector is mainly composed of dirty firms. Despite this tax incidence effect on price, it is straightforward to determine whether the implementation of the carbon tax always deteriorates the margin of the most polluting firms, which also holds for the less polluting firms if and only if

$$
n<\frac{\varepsilon_{c}}{\varepsilon_{d}-\varepsilon_{c}}
$$


Because it is more realistic to consider that the tax incidence effect is not strong enough for the impact of the carbon tax on firms' margin to be negative, we assume hereafter that the latter inequality holds.

Despite the positive impact of trade costs on the price level (because trade costs protect against foreign competition), the overall impact of trade costs on the export margin is negative. At this stage, recall that our aim is to analyze how, by altering the spatial distribution of dirty and clean firms, a global carbon tax may affect emissions. To this end, we must account for the significant share of $\mathrm{CO}_{2}$ emissions that are reputed to be embodied in trade. According to Weber et al. (2008), approximately one-third of Chinese emissions were caused by the production of exports in 2005 versus $12 \%$ in 1987 and $21 \%$ in 2002 . In the following, we focus on equilibrium configurations in which bilateral trade flows occurs. As a consequence, trade cost values are assumed to be low enough for exports to be profitable for firms - whatever their type- their distribution across countries and the overall distribution across types. Two scenarios must be considered to define this trade condition.

i) If $t<\bar{t}$ (clean firms have the highest marginal cost), the trade condition stipulates that the export margin of a clean firm on the largest market $\left(p_{h}^{c}-m-\tau-t \varepsilon_{c}\right)$ is positive when all other firms are dirty $(\mu=1)$ and located in the largest country as well $\left(n_{f}=0\right)$; that is, when $\tau<\tau_{\text {trade }}$ (see below).

(ii) If $t>\bar{t}$ (dirty firms have the highest marginal cost), the trade condition requires that the export margin of a dirty firm on the largest market $\left(p_{h}^{d}-\tau-t \varepsilon_{d}\right)$ be positive when all other firms are clean $(\mu=0)$ and located in the largest country as well $\left(n_{f}=0\right)$; that is, when $\tau<\tau_{\text {trade }}^{\prime}$

We summarize this trade condition by the following inequality:

$$
\tau<\min \left\{\tau<\tau_{\text {trade }}, \tau<\tau_{\text {trade }}^{\prime}\right\}
$$

After performing calculations, we obtain the following:

$$
\begin{aligned}
\tau_{\text {trade }} & =\frac{a-m(n+1)+n t\left(\varepsilon_{d}-\varepsilon_{c}\right)-t \varepsilon_{c}}{n+1} \\
\tau_{\text {trade }}^{\prime} & =\tau_{\text {trade }}+\frac{2 n+1}{n+1}\left(m+t\left(\varepsilon_{c}-\varepsilon_{d}\right)\right) .
\end{aligned}
$$

Hereafter, we assume $a>m(n+1)-t\left(n\left(\varepsilon_{d}-\varepsilon_{c}\right)-\varepsilon_{c}\right)$ such that the abovementioned thresholds are positive regardless of the carbon tax level. 
Then, substituting for the equilibrium prices in the output choices, we obtain the equilibrium output in the short run. For clean firms, the quantities are described as follows:

$$
x_{h h}^{c}=\frac{\lambda l}{\beta}\left[\frac{a+n_{f} \tau+n \omega}{n+1}-\left(m+t \varepsilon_{c}\right)\right] \text { and } x_{h f}^{c}=\frac{(1-\lambda) l}{\beta}\left[\frac{a+n \omega+n_{h} \tau}{n+1}-\left(m+t \varepsilon_{c}+\tau\right)\right]
$$

for a firm located in country $H$ and

$$
x_{f f}^{c}=\frac{(1-\lambda) l}{\beta}\left[\frac{a+n_{h} \tau+n \omega}{n+1}-\left(m+t \varepsilon_{c}\right)\right] \text { and } x_{f h}^{c}=\frac{\lambda l}{\beta}\left[\frac{a+n \omega+n_{f} \tau}{n+1}-\left(m+t \varepsilon_{c}+\tau\right)\right]
$$

for a firm located in country $F$.

Mirror expressions hold for dirty firms, for which $\varepsilon_{c}$ is replaced by $\varepsilon_{d}$ and $m$ by 0 . It is observed that because of trade costs, a firm sells less on the export market than its indigenous rival does, $x_{f h}^{k}=x_{h h}^{k}-l \lambda \tau / \beta$, regardless of the firm's type. Moreover, sales on a given market are higher for the type of firm that enjoys the lowest marginal cost.

For clarity, we analyze the effect of the carbon tax under the two scenarios (i) and (ii) separately. We start in sections 3 and 4 by analyzing the scenario in which the carbon tax remains within the interval $t<\bar{t}$, implying that clean firms have the highest marginal cost. Scenario (ii) is discussed in Appendix 4.

\section{Long-run spatial equilibrium}

In this section, we assume that $t \in(0, \bar{t}]$. Equation (3) indicates that this scenario may occur because the marginal labor requirement of clean firms is large, the difference in the per-unit emissions of the two types of firms is not large and/or the carbon tax is low. Consequently, $\tau_{\text {trade }}^{\prime}(t)>\tau_{\text {trade }}(t)$, yielding the following simplified trade condition:

$$
\tau<\tau_{\text {trade }}(t)
$$

In the long run, the number of firms located in each country is endogenously determined by the condition that no firm has an incentive to move. Moreover, the equilibrium rate of return to capital is determined by the zero-profit condition. In other words, the operating profits evaluated at the equilibrium prices and quantities are completely absorbed by the return to capital, and no firm can profitably enter the market. Formally, we have 


$$
\begin{aligned}
& r_{h}^{c}=\frac{\lambda l}{\beta}\left[p_{h}^{*}-m-t \varepsilon_{c}\right]^{2}+\frac{(1-\lambda) l}{\beta}\left[p_{f}^{*}-m-t \varepsilon_{c}-\tau\right]^{2} \\
& r_{f}^{c}=\frac{\lambda l}{\beta}\left[p_{h}^{*}-m-t \varepsilon_{c}-\tau\right]^{2}+\frac{(1-\lambda) l}{\beta}\left[p_{f}^{*}-m-t \varepsilon_{c}\right]^{2}
\end{aligned}
$$

Similar expressions hold for dirty firms, for which $\varepsilon_{c}$ is replaced by $\varepsilon_{d}$ and $m$ by 0 .

Now, we can analyze the spatial differences in return to capital for each type of firm to determine where capital owners decide to invest their capital. The spatial differences in the net return to capital $\triangle r^{i}=r_{h}^{i}-r_{f}^{i}$ are as follows:

$$
\begin{aligned}
\Delta r^{c} & =l \tau \frac{\left(n-2 n_{h}-2 \lambda+1\right) \tau+2(2 \lambda-1)\left(a-(n+1)\left(m+t \varepsilon_{c}\right)+n \omega\right)}{\beta(n+1)} \\
\Delta r^{d} & =l \tau \frac{\left(n-2 n_{h}-2 \lambda+1\right) \tau+2(2 \lambda-1)\left(a-(n+1) t \varepsilon_{d}+n \omega\right)}{\beta(n+1)}
\end{aligned}
$$

where $a-(n+1)\left(m+t \varepsilon_{c}\right)+n \omega$ and $a-(n+1) t \varepsilon_{d}+n \omega$ are positive for all positive values of $\tau_{\text {trade }}$. Now, let us denote by $s_{k}$ the share of $k$-type firms located in country $\mathrm{H}$, such that the number of firms in country $\mathrm{H}$ can be written as $n_{h}=\mu n s_{d}+(1-\mu) n s_{c}$ where $(1-\mu) s_{c} n$ and $\mu s_{d} n$ represent the number of clean and dirty firms in country $\mathrm{H}$, respectively. Replacing $n_{h}$ by $\mu n s_{d}+(1-\mu) n s_{c}$ and the average marginal cost $\omega$ by its value in (8) and (9), we can analyze how these variables react to a change in the spatial distribution of $k$-type firms, $s_{k}$, or in the distribution of firms across types, $\mu$. It is straightforward to verify that $d \Delta^{k} / d s_{k}<0$ $\forall k=c, d$ due to higher competition. Thus, location equilibria are stable.

The carbon tax triggers two opposing forces on the spatial difference in return to capital:

$$
\frac{\partial \Delta r^{k}}{\partial t}=\frac{2 l \tau}{\beta}(2 \lambda-1)[\underbrace{\frac{\partial p_{h}}{\partial t}}_{\text {tax incidence }(+)}-\underbrace{\frac{\partial t \varepsilon_{i}}{\partial t}}_{\text {marginal cost }(-)}], k=c, d
$$

In the presence of market size asymmetry, $\lambda>1 / 2$, the tax incidence force exacerbates the difference in returns to capital across countries, whereas the impact of the carbon tax on the marginal cost has the opposite sign. The net impact is always negative for dirty firms, whose tax burden is raised by their high emissions, which is also the case for clean firms as long as the effect on the marginal cost dominates that on the tax incidence, as we assumed in (4). Consequently, we have 


$$
\frac{\partial \Delta r^{c}}{\partial t}<0 \text { and } \frac{\partial \Delta r^{d}}{\partial t}<0
$$

More importantly, a carbon tax erodes the benefit of being in the large country more for the dirty firms than for the clean ones :

$$
\left|\frac{\partial \Delta r^{c}}{\partial t}\right|<\left|\frac{\partial \Delta r^{d}}{\partial t}\right| .
$$

Hence, when different market sizes are considered, a global carbon tax is not a spatially neutral policy instrument. Because the tax amount paid is proportional to the individual output (the carbon tax is a quantity tax), the location in the large market becomes more costly and some firms may relocate towards the small one with the aim of reducing the tax burden. Consequently, the introduction of such taxation increases the attractiveness of the small country. This mechanism takes place in the presence of homogeneous technologies (Exbrayat et al, 2013) and is further accentuated for dirty firms when heterogeneous technologies coexist.

Finally, we check that

$$
\Delta r^{c}-\Delta r^{d}=2 l \tau(2 \lambda-1) \frac{t\left(\varepsilon_{d}-\varepsilon_{c}\right)-m}{\beta}<0
$$

which is negative because (3). Hence, because of a scale economies effect, the spatial difference in net return to capital between the large and small countries is higher for dirty firms that keep enjoying the lowest marginal cost after taxation. Because $\Delta r^{c}$ is always smaller than $\Delta r^{d}$, the long-run equilibrium location of firms cannot involve an interior configuration with a partial coagglomeration between the two countries for each type of firms, that is, $\Delta r^{c}=$ $\Delta r^{d}=0$. Importantly, all firms can never agglomerate in the small country because for $n_{h}=0$, we have $\Delta r^{c}>0$ and $\Delta r^{d}>0$, implying that each firm, whether dirty or clean, has an incentive to move to the large country.

We are now in a position to describe location equilibria in the long run. For this purpose, let us first define the equilibrium spatial configuration of firms when a carbon tax is absent. We first demonstrate in Appendix 1 that $n-2 n_{h}-2 \lambda+1$ is negative such that the spatial difference in return to capital decreases with trade costs, regardless of the type of firm (see (8) and (9)). Therefore, let us define the following: 


$$
\begin{aligned}
\tau^{a} & =2(2 \lambda-1) \frac{a-m(n \mu+1)}{n+2 \lambda-1} \\
\tau^{c} & \equiv 2(2 \lambda-1) \frac{a-m(n \mu+1)}{n(2 \mu-1)+2 \lambda-1} \\
\tau^{d} & \equiv 2(2 \lambda-1) \frac{a+n(1-\mu) m}{n(2 \mu-1)+2 \lambda-1}
\end{aligned}
$$

where $\tau_{a}$ and $\tau_{c}$ are obtained by requiring $\Delta r^{c}=0$ at spatial configurations $\left(s_{c}=1 ; s_{d}=1\right)$ and $\left(s_{c}=0 ; s_{d}=1\right)$, respectively, whereas $\tau_{d}$ is obtained by requiring $\Delta r^{d}=0$ at spatial configurations $\left(s_{c}=0 ; s_{d}=1\right)$. We can easily check that $\tau^{a}<\tau^{c}<\tau^{d}$.

To define the possible spatial configurations, let us consider the following:

$$
\begin{aligned}
& \tilde{s}_{c}=\frac{1}{2} \frac{2 \mu-1}{\mu-1}+(2 \lambda-1) \frac{1}{2} \frac{2(a-m)-2 n \mu m-\tau}{n \tau(1-\mu)} \\
& \tilde{s}_{d}=\frac{1}{2 \mu}+(2 \lambda-1) \frac{1}{2} \frac{2 a+22 n m n m(1-\mu)-\tau}{n \tau \mu}
\end{aligned}
$$

Then, as the level of trade cost decreases because of the process of trade integration, the possible spatial configurations are as follows:

(i) partial selection of dirty firms and agglomeration of clean firms in the smaller country $\left(0, \tilde{s}_{d}\right)$ when $\tau>\tau^{d}$;

(ii) perfect selection of dirty firms and clean firms $(0,1)$ when $\tau^{d} \geqslant \tau>\tau^{c}$;

(iii) partial selection of clean firms and agglomeration of dirty firms in the larger country $\left(\tilde{s}_{c}, 1\right)$ when $\tau^{c} \geqslant \tau>\tau^{a}$

(iv) co-agglomeration in the larger country $(1,1)$ when $\tau \leqslant \tau^{a}$.

We prove in Appendix 1 that $\tau^{d}<\tau_{\text {trade }}$ such that all of the abovementioned spatial patterns are compatible with the trade feasibility condition. ${ }^{8}$ To understand this result, recall the location forces that explain why we move from the most dispersed spatial pattern to more agglomerated configurations. On the one hand, the market size encourages firms to locate in the larger country. Moreover, the derivatives $d \Delta r^{d} / d \lambda>d \Delta r^{c} / d \lambda>0$ show that the market size effect is stronger for the dirty firms because they benefit from a lower marginal cost. We verify that $d^{2} \Delta r^{c} / d \lambda d \tau=d^{2} \Delta r^{c} / d \lambda d \tau<0$, implying that this market size effect increases with the decrease in trade costs. On the other hand, we observe that $d \Delta r^{d} / d n_{h}=d \Delta r^{c} / d n_{h}<0$ (see. (8) and (9)) and $d^{2} \Delta r^{c} / d n_{h} d \tau=d^{2} \Delta r^{d} / d n_{h} d \tau<0$. Thus, competition acts as a dispersion

\footnotetext{
${ }^{8} \mathrm{~A}$ similar conclusion is reached under monopolistic competition in Okubo et al (2010).
} 
force; however, decreasing trade costs weakens this force, whereas it amplifies the agglomeration force. This reasoning helps explain the shift from spatial configuration (i) to (ii), (ii) to (iii) and from (iii) to (iv). During this process, dirty firms are the first ones to move toward the larger country. Indeed, they have the lowest marginal cost and thus are both more attracted by the large country and less sensitive to the higher competition within this country.

We now turn attention to the long-run equilibrium location in the presence of a carbon tax. Because the introduction of a carbon tax modifies the spatial differences in return to capital, the threshold levels of trade costs are now expressed by

$$
\begin{aligned}
\tau_{a}(t) & \equiv \tau_{a}-t A_{a} \\
\tau_{c}(t) & \equiv \tau_{c}-t A_{c} \\
\tau_{d}(t) & \equiv \tau_{d}-t A_{d}
\end{aligned}
$$

with

$$
\begin{aligned}
A_{a} & \equiv 2(2 \lambda-1) \frac{\varepsilon_{c}+n \mu\left(\varepsilon_{c}-\varepsilon_{d}\right)}{n+2 \lambda-1} \\
A_{c} & \equiv 2(2 \lambda-1) \frac{\varepsilon_{c}+n \mu\left(\varepsilon_{c}-\varepsilon_{d}\right)}{-n+2 \lambda+2 n \mu-1} \\
A_{d} & \equiv 2(2 \lambda-1) \frac{\varepsilon_{d}+n\left(\varepsilon_{d}-\varepsilon_{c}\right)(1-\mu)}{-n+2 \lambda+2 n \mu-1}
\end{aligned}
$$

and $A_{d}>A_{c}>A_{a}>0$. Note that $\tau_{a}(t)<\tau_{c}(t)<\tau_{d}(t)$ for any $t$, and each one of this threshold values of $\tau$ decreases with $t$. Consequently, the higher the carbon tax is, the smaller the trade cost threshold that triggers the shift from one spatial configuration to the other becomes. Thus, abstracting for a moment from the trade feasibility condition, a positive carbon tax reduces the attractiveness of the larger country (see equation (10)). Indeed, the carbon tax is a quantity tax that ultimately reduces the incentive to locate in the larger country to produce on a larger scale. In other words, even when levied at the same rate, the carbon tax distorts the location choices of heterogeneous mobile firms.

Similarly to the scenario involving a zero carbon tax, we can now define spatial configurations that may arise (see Figure 1). For this purpose, let us consider the following: 


$$
\begin{aligned}
& \tilde{s}_{c}^{t}=\tilde{s}_{c}-t(2 \lambda-1) \frac{\varepsilon_{c}+n \mu\left(\varepsilon_{c}-\varepsilon_{d}\right)}{n \tau(1-\mu)}, \\
& \tilde{s}_{d}^{t}=\tilde{s}_{d}-t(2 \lambda-1) \frac{\varepsilon_{d}+n\left(\varepsilon_{d}-\varepsilon_{c}\right)(1-\mu)}{n \tau \mu} .
\end{aligned}
$$

It follows that the possible spatial configurations are as follows:

(i) Agglomeration of clean firms in the smaller country and partial selection of dirty firms $\left(0, \tilde{s}_{d}^{t}\right)$ when $\tau>\tau_{d}(t)$;

(ii) Perfect selection of dirty firms in the larger country and clean firms in the smaller country $(0,1)$ when $\tau_{d}(t) \geqslant \tau>\tau_{c}(t)$;

(iii) Partial selection of clean firms and agglomeration of dirty ones in the larger country $\left(\tilde{s}_{c}^{t}, 1\right)$ when $\tau_{c}(t) \geqslant \tau>\tau_{a}(t)$;

(iv) Co-agglomeration in the larger country $(1,1)$ when $\tau \leqslant \tau_{a}(t)$.

Can all these spatial configurations arise as location equilibria? To answer this question, we must analyze whether the configurations are compatible with bilateral trade flows. The following proposition shows that both the level of taxation and the market size asymmetry affect the set of equilibrium candidates:

Proposition 1 Given $t \in[0 ; \bar{t})$ and $\tau \in\left[0 ; \tau_{\text {trade }}\right)$, there exists threshold values of the carbon tax $t_{1}, t_{2}$ and $t_{3}$ such that

(a) if $t \leq t_{1}$, then all spatial configurations $(1,1),\left(\tilde{s}_{c}^{t}, 1\right),(0,1),\left(0, \tilde{s}_{d}^{t}\right)$ are location equilibria;

(b) if $t_{1}<t \leq t_{2}$, then spatial configurations $(1,1),\left(\tilde{s}_{c}^{t}, 1\right),(0,1)$ are equilibria locations;

(c) if $\lambda \geqslant(3 n+1) /(4 n+2)$ and $t_{2}<t \leqslant t_{3}$ or if $\lambda<(3 n+1) /(4 n+2)$ and $t_{2}<t \leqslant \bar{t}$, then spatial configurations $(1,1)$ and $\left(\tilde{s}_{c}^{t}, 1\right)$ are location equilibria;

(d) if $\lambda \geqslant(3 n+1) /(4 n+2)$ and $t>t_{3}$, then the only location equilibrium is $(1,1)$.

\section{Proof. See Appendix 2.}

The foregoing proposition states that low levels of the carbon tax, i.e., $t \leq t_{1}$, leave the type of spatial configurations that would arise in the absence of any carbon tax unchanged. By contrast, as the carbon taxes exceeds the threshold value $t_{1}$, certain spatial configurations with trade cease to be stable equilibria because international trade ceases to be profitable. This result can be explained as follows. Different spatial configurations arise depending on the 
weight of two traditional forces shaping the location choices: the market size and the intensity of competition. Introducing a carbon tax weakens the market size effect. As a result, the higher the carbon tax is, the smaller each of the threshold values of trade costs becomes (with $\left.d \tau_{d}(t) / d t<d \tau_{c}(t) / d t<d \tau_{a}(t) / d t<0\right)$. Thus, ceteris paribus,

Corollary 1 A global carbon tax weakens agglomeration forces and favors the emergence of dispersed equilibria of firms' location.

As discussed in section 3, this effect has repercussions for the level of pollution in both countries.

However, this is not the end of the story. On the one hand, a global carbon tax reduces most the trade conditions that define agglomerated configuration favoring dispersion; on the other, the tax does render the trade condition more binding $\left(d \tau_{\text {trade }} / d t<0\right)$ such that threshold values $\tau_{c}(t)$ and $\tau_{d}(t)$ might become higher than $\tau_{\text {trade. }}$ In this case, the global carbon tax (in the presence of strong asymmetry in country size) works against dispersion. In fact, the most dispersed spatial configurations become incompatible with the trade condition, whereas they are compatible without such a tax. We call this the no-trade effect, which occurs when $t>t_{1}$ (i.e., $\tau_{d}(t)>\tau_{\text {trade }}$ ), when $t>t_{2}$ (i.e., $\left.\tau_{c}(t)>\tau_{\text {trade }}\right)$ or $t>t_{3}$ (i.e., $\left.\tau_{a}(t)>\tau_{\text {trade }}\right)$.

Figure 1 illustrates the selection of location equilibria compatible with the trade condition when countries' size satisfy either $\lambda<(3 n+1) /(4 n+2)$ (left panel) or $\lambda>(3 n+1) /(4 n+2)$ (right panel), respectively. We summarize the result as follows:

Corollary 2 A high global carbon tax favors agglomeration when market sizes are strongly asymmetric.

Hence, introducing a carbon tax may crucially affect the set of possible location equilibria and, in turn, the level of emissions. Now, the level of pollution corresponding to each spatial configuration remains to be analyzed.

\section{Pollution}

To proceed with the analysis of global pollution, we evaluate total emissions stemming from each spatial configuration when $t=0$ and $t>0$. Considering these two cases is essential for the identification of various effects of a carbon tax on pollution. 


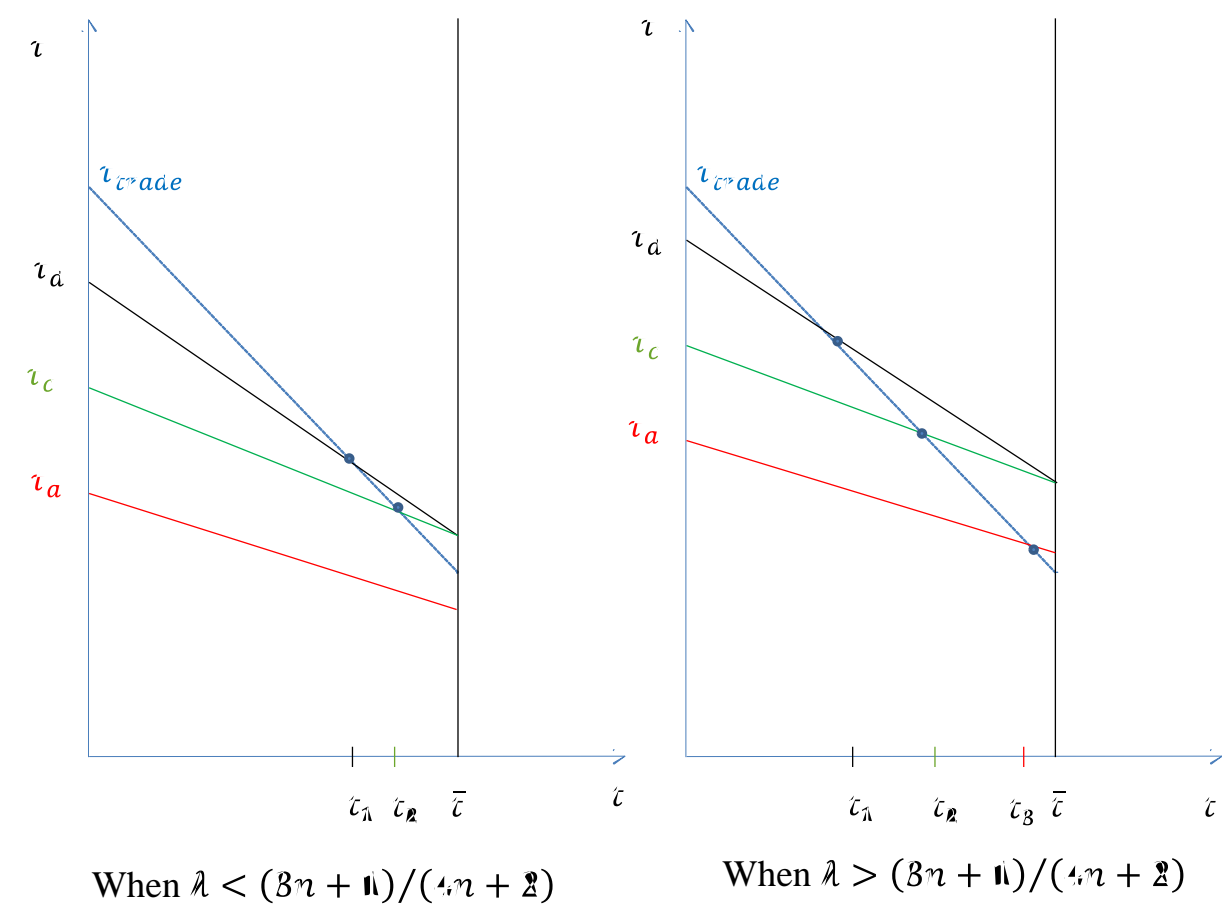

Figure 1: Location equilibria for all $t<\bar{t}$

\subsection{Global emissions in the absence of taxation}

The function of global emissions for a given spatial distribution of clean and dirty firms $\left(E_{c}+E_{d}\right)$ can be expressed as follows:

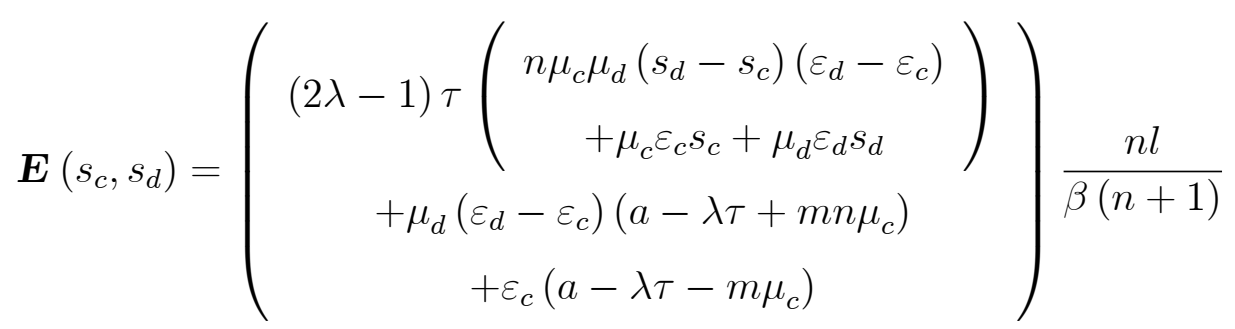

where $s_{d}>s_{c}$ regardless of the equilibrium spatial configuration as long as $t \in(0, \bar{t}]$. We can now incorporate the equilibrium values of $s_{c}$ and $s_{d}$ to analyze the evolution of global emissions as we move from one spatial configuration to another.

Comparing the level of global emissions at the spatial configuration i) with ii), ii) with iii), and finally iii) with iv), at the market equilibrium, we obtain the following: 


$$
\begin{aligned}
\boldsymbol{E}(0,1) & \gtrless \boldsymbol{E}\left(0, \tilde{s}_{d}\right) \text { for all } \tau \gtrless \tau_{d} \\
\boldsymbol{E}\left(\tilde{s}_{c}, 1\right) & \gtrless \boldsymbol{E}(0,1) \text { for all } \tau \lessgtr \tau_{c} \\
\boldsymbol{E}(1,1) & \gtrless \boldsymbol{E}\left(\tilde{s}_{c}, 1\right) \text { for all } \tau \gtrless \tau_{a}
\end{aligned}
$$

For all spatial configurations, the global emissions decrease with the level of trade costs but not to the same extent. We easily check that $d \boldsymbol{E}(1,1) / d \tau>d \boldsymbol{E}(0,1) / d \tau>d \boldsymbol{E}\left(s_{c}, 1\right) / d \tau>$ $\boldsymbol{E}\left(0, \tilde{s}_{d}\right)$. The following graph illustrates the evolution of global emissions.

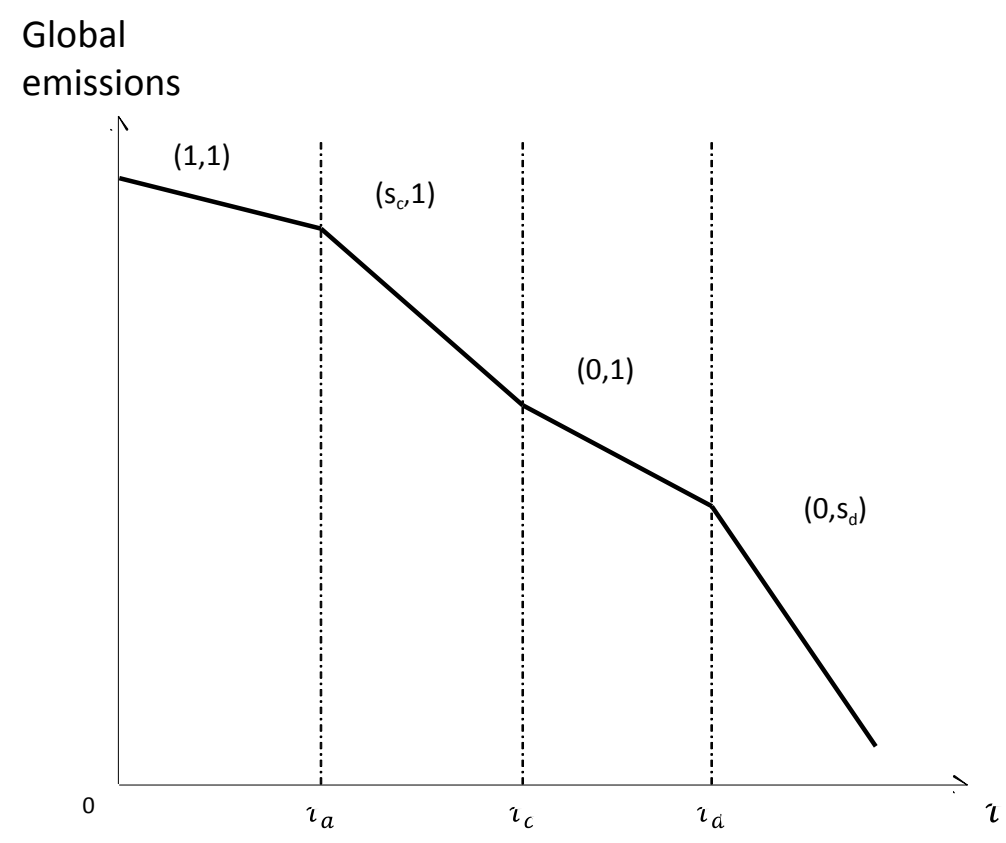

Figure 2: Global emissions and trade cost without carbon taxation

Trade liberalization favors agglomeration in the larger country, which is also the most polluting spatial configuration, suggesting that trade liberalization is detrimental to the environment. Two effects underlie this specific path of pollution. First, for a given spatial pattern, trade liberalization boosts the output per firm and thereby the level of emissions. Second, as is standard in trade and location models, trade liberalization pushes for relocations from the small to the larger country because of the attractiveness of its market size. Because average scale of production is higher in this country, such relocations amplify emissions. Interestingly, the two effects are at work in configurations (i) and (iii), leading to a more intense increase in the level of pollution. By contrast, only the quantity effect occurs in configurations (ii) and (iv), leading to a less accentuated rise in the level of pollution. 


\subsection{Global emissions in the presence of a carbon tax}

We can now analyze the environmental effects of the implementation of a global carbon tax. To address this issue, we start with the spatial configurations $(1,1)$ and $(0,1)$ :

$$
\begin{aligned}
\boldsymbol{E}^{t}(1,1) & =\boldsymbol{E}(1,1)-t \Lambda \text { and } \boldsymbol{E}^{t}(0,1)=\boldsymbol{E}(0,1)-t \Lambda \\
\text { with } \Lambda & =n l \frac{\mu\left(\varepsilon_{d}-\varepsilon_{c}\right)\left(\varepsilon_{c}+\varepsilon_{d}+n\left(\varepsilon_{d}-\varepsilon_{c}\right)(1-\mu)\right)+\varepsilon_{c}^{2}}{\beta(n+1)}
\end{aligned}
$$

We check that $\Lambda$ is positive under the assumption (4), such that the carbon tax reduces the global level of emissions. Regarding these two spatial configurations, the reduction in emissions is exclusively driven by the adjustment of the individual output of each type of firm (because $\tilde{s}_{d}^{t}$ and $\tilde{s}_{c}^{t}$ are constant). This Pigouvian effect amounts to $t \Lambda$.

Turning our attention to total emissions in the two other spatial configurations such that at least one type of firm is partially agglomerated in the larger country. , we obtain

$$
\begin{aligned}
\boldsymbol{E}^{t}\left(\tilde{s}_{c}^{t}, 1\right) & =\boldsymbol{E}\left(\tilde{s}_{c}, 1\right)-t(\Lambda+\Upsilon) \text { and } \boldsymbol{E}^{t}\left(0, \tilde{s}_{d}^{t}\right)=\boldsymbol{E}\left(0, \tilde{s}_{d}\right)-t(\Lambda+\Theta) \\
\text { with } \Upsilon & =l(2 \lambda-1)^{2} \frac{\left(\varepsilon_{c}+n \mu\left(\varepsilon_{c}-\varepsilon_{d}\right)\right)^{2}}{\beta(n+1)} \\
\text { and } \Theta & =l(2 \lambda-1)^{2} \frac{\left(\varepsilon_{d}+n\left(\varepsilon_{d}-\varepsilon_{c}\right)(1-\mu)\right)^{2}}{\beta(n+1)}
\end{aligned}
$$

Again, the implementation of a carbon tax clearly reduces emissions. However, it does so through both a Pigouvian effect (captured by $\Lambda$ ) and a relocation effect (captured by $\Upsilon$ and $\Theta$ ). Indeed, recall that $\tilde{s}_{c}^{t}$ and $\tilde{s}_{d}^{t}$ decline with $t$ because the carbon tax reduces the spatial difference in returns to capital (through its negative impact on the difference in net marginal cost between dirty and clean firms). Therefore, a global carbon tax reduces the spatial concentration of clean and dirty firms in the larger country. Importantly, this relocation effect is stronger in the spatial configuration with partial concentration of dirty firms $(\Theta>\Upsilon)$ because the carbon tax exerts a stronger effect on the firms' margin than on the margin of clean firms.

Finally, let us analyze the evolution of global emissions as we move along the equilibrium path of spatial configurations. Assume for a moment that the carbon tax does not exceed the threshold value $t_{1}$ and thus bilateral trade flows may be observed under all four spatial configurations. We can rank global emissions along the equilibrium path of spatial configurations as follows: 


$$
\boldsymbol{E}^{t}(1,1)>\boldsymbol{E}^{t}\left(\tilde{s}_{c}, 1\right)>\boldsymbol{E}^{t}(0,1)>\boldsymbol{E}^{t}\left(0, \tilde{s}_{d}\right)
$$

Therefore, although the function is shifted down because of the efficiency of the carbon tax, global emissions follows the same pattern as in the absence of it: They increase with trade liberalization and with a more agglomerated pattern in the larger market (see. Figure 2).

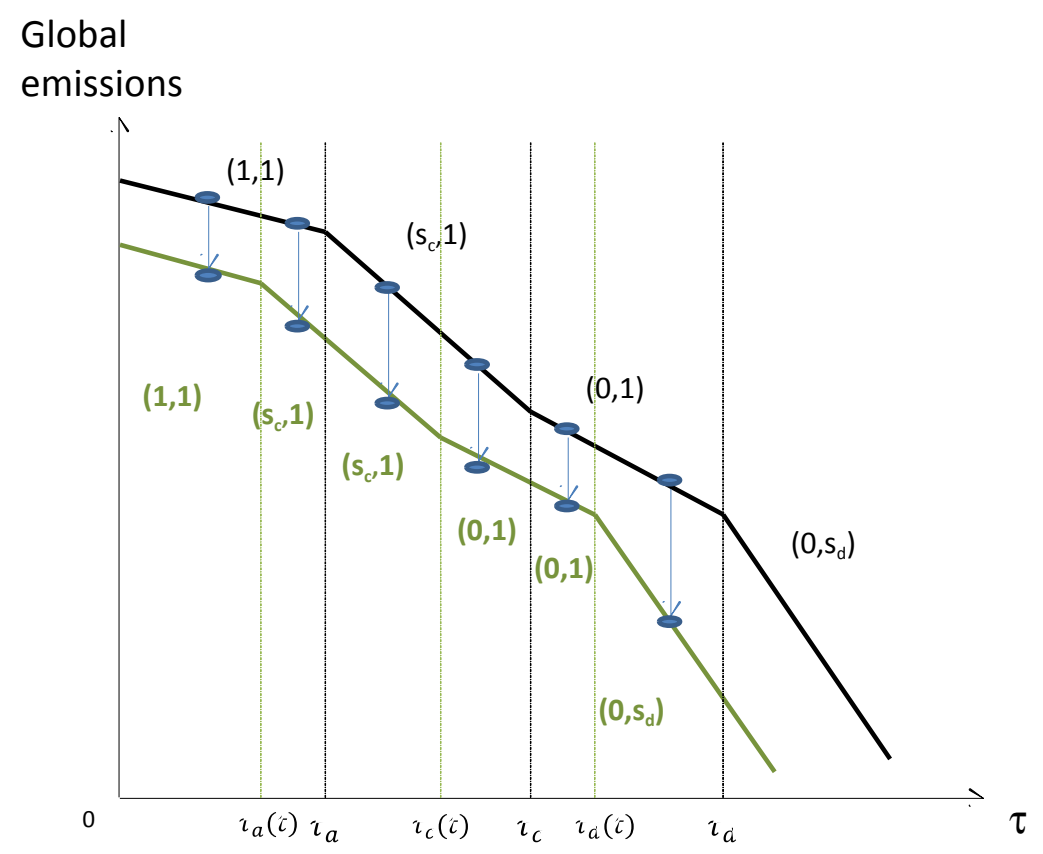

Figure 3: Global emissions and trade cost with a carbon tax

However, note that the magnitude of the decrease in emissions strongly depends on the initial spatial equilibrium and whether this spatial pattern is stable to the introduction of the carbon tax. Indeed, taxing emissions affects the threshold levels of trade costs, which all decrease and thus shift to the left. As a consequence, certain initial spatial configurations become unstable, and some firms may relocate to keep their profitability unchanged. This is the relocation effect that arises when the trade cost belongs to the intervals $\left(\tau_{a}(t), \tau_{a}\right),\left(\tau_{c}(t), \tau_{c}\right)$ or $\left(\tau_{d}(t), \tau_{d}\right)$. It can be observed that this effect is large, and thus amplifies the efficiency of the carbon tax, when the spatial pattern shifts from the co-agglomeration $(1,1)$ or perfect selection $(0,1)$ to a pattern that combines partial selection for one type of firm and agglomeration for the other $\left(\left(s_{c}, 1\right)\right.$ or $\left.\left(0, s_{d}\right)\right)$. For these two configurations, Pigouvian and relocation effects accumulate and reinforce the effect of the tax on pollution.

For example, consider the shift from $(1,1)$ to $\left(s_{c}, 1\right)$. The relocation of some clean firms to the smaller market has two consequences. First, the new spatial distribution of clean firms 
is more environmentally friendly because $d E_{c}^{t} / d s_{c}>0$. Second, the most polluting firms, fully concentrated in the larger market, face less competition in this market and thereby produce and pollute more $\left(d E_{d}^{t} / d s_{c}<0\right)$. Put differently, the effect on environment is positive for clean firms, whereas it is negative for dirty ones. It is straightforward to check that $\left|d E_{c}^{t} / d s_{c}\right|>\left|d E_{d}^{t} / d s_{c}\right|$ for all $n<\varepsilon_{c} / \varepsilon_{d}-\varepsilon_{c}$ such that the positive effect dominates. For the same reasons, pollution strongly declines within the range $\left(\tau_{d}(t), \tau_{d}\right)$ : The relocation of some dirty firms from the larger to the smaller market increases pollution from clean firms but decreases pollution from dirty ones to a larger extent.

These elements suggest that the efficiency of a global carbon tax policy is closely related to both the initial spatial equilibrium and the level at which the tax is set. The following proposition summarizes our results:

Proposition 2 Assume a level of trade cost $\tau \in\left(0, \tau_{a}\right)$ or $\tau \in\left(\tau_{c}, \tau_{d}\right)$ such that co-agglomeration $(1,1)$ or perfect selection $(0,1)$ is the initial spatial equilibrium. Starting from such configurations, a global carbon tax will have a maximum effect on pollution if it gives rise to relocations from the larger market to the smaller one.

The above-described proposition illustrates the possibility that a carbon taxation induces not only the Pigouvian effect, which reduces pollution in each spatial configuration, but also urges the relocation of firms from one country to the other, changing the type of spatial equilibrium that arises at certain levels of trade cost.

Finally, as Proposition 1 states, in the presence of a carbon tax, some spatial configurations may no longer arise as location equilibria. Indeed, a relatively high tax pressure might exclude some spatial equilibria because trade becomes unprofitable. If the carbon tax reaches and exceeds the threshold value $t_{1}$, the level of emissions may be the result of three effects: the Pigouvian and, possibly, the relocation and no-trade effects. If the last effect prevails, then one or more location equilibria disappear.

It is worth stressing that the third effect concerns the most environmentally friendly configurations. As stated by Proposition 1, scenario (iv) will no longer be among the set of location equilibria for this level of the carbon tax. Thus, the pollution curves appear as shown below:

We summarize our results in the following proposition. 


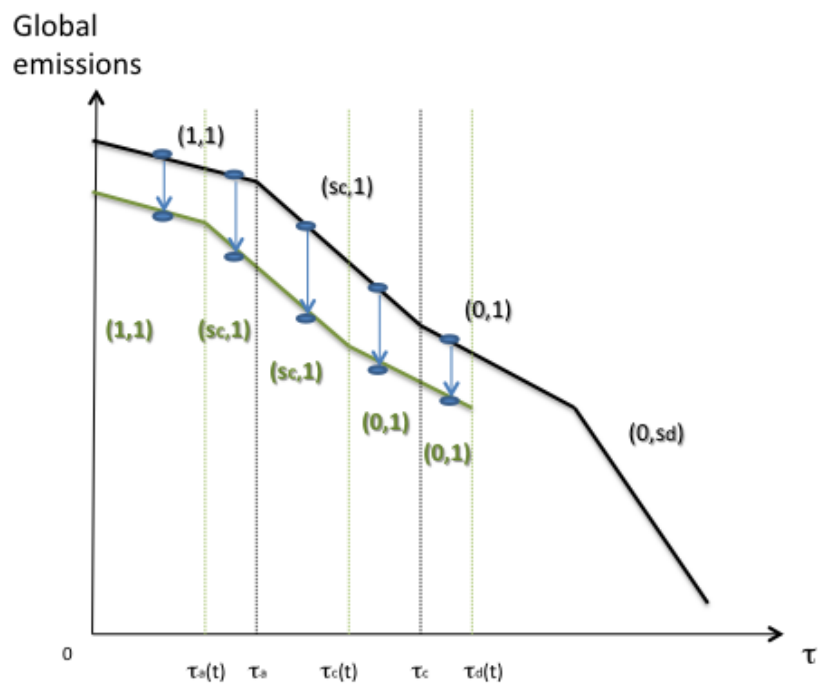

Proposition 3 A relatively small global carbon tax, $t \leq t_{1}$, decreases the total level of pollution through a Pigouvian effect and a relocation effect, leaving all spatial configurations to arise as equilibrium locations. Under a sufficiently high level of the global carbon tax, $t>t_{3}$, the tax renders trade inconvenient, favoring agglomeration.

To conclude, we show that as long as the carbon tax does not exceed a threshold value (namely $t_{1}$ ), the policy has only positive effects for the environment. It lowers emissions in any spatial configuration and induces environmentally friendly spatial relocations. Nonetheless, there exists a threshold value, i.e., $t_{1}$, above which the effects of taxation are more complex because the set of candidate equilibria is modified. More precisely, the most environmentally friendly spatial configurations can be removed.

\section{Conclusion}

This paper investigates the ability of a fully harmonized carbon tax to curb carbon emissions in a globalized economy characterized by an uneven spatial distribution of heterogeneous firms. Our results challenge the claim that a global carbon tax could succeed in improving the quality of environment without raising competitiveness concerns.

We first show that regardless of its level, a global carbon tax might encourage some firms to relocate their activity. Importantly, the level of the carbon tax matters for the direction of the relocation and its impact on global emissions. When the carbon tax is low enough, firms relocate to the smaller country to pay lower taxes by reducing their output. In addition to 
the Pigouvian effect of the carbon tax, this relocation reduces global emissions by promoting a less concentrated spatial distribution of activities. Interestingly, this relocation strategy never involves clean and dirty firms at the same time. Specifically, low-cost firms relocate to the smaller country at an earlier stage of trade liberalization than high-cost firms do. Indeed, because they suffer a higher post-tax marginal cost, the latter are both less attracted by the large country and more sensitive to the higher competition within this country. If, however, the carbon tax is too high, then firms' profitability on the export market can be threatened, and they react by relocating to the larger country to maintain their export activity. In such a case, the Pigouvian effect of the carbon tax can be counteracted by the relocation effect, giving rise to a more polluting spatial distribution of firms.

\section{Appendices}

\section{Appendix 1: Equilibrium spatial locations in absence of carbon tax}

To prove that spatial configurations (i),(ii),(iii) and (iv) are equilibria locations when $t=0$, we simply need to prove that the trade condition evaluated at $t=0$ is such that $\tau_{\text {trade }}(0) \geq \tau^{d}$. If this condition is satisfied then there exist ranges of values of $\tau$ such that any of the four spatial scenarios can arise as an equilibrium. Recall that $\tau^{d}=2(2 \lambda-1) \frac{a+n m(1-\mu)}{-(n-2 \lambda-2 n \mu+1)}$ and $\tau_{\text {trade }}(0)=$ $\frac{a-m(n+1)}{n+1}$, where $-(n-2 \lambda-2 n \mu+1)>0$ for the positivity of $\tau^{d}$. It is easily checked that $\tau^{d}$ depends negatively on $\mu$ hence if $\tau_{\text {trade }}(0) \geq \tau^{d}$ when $\mu=0$, then $\tau_{\text {trade }}(0) \geq \tau^{d}$ is true for any $\mu$. Hence, assuming $\mu=0$, and directly comparing $\tau^{d}$ and $\tau_{\text {trade }}(0)$ we obtain that $\tau_{\text {trade }}(0) \geq \tau^{d}$ iff $(n-2 \lambda+1)>0$ and $\left(2 a+2 m+4 m n^{2}+4 a n+6 m n\right) \lambda-\left(a+m+3 m n^{2}+a n+4 m n\right)>0$. The first inequality is true because $n>1$ and $\lambda<1$. The second expression is positive as long as $\lambda>\frac{1}{2}$, which is true by assumption. In fact the second expression is positive for $\lambda=\frac{1}{2}$ and being increasing in $\lambda$, it remains positive for the whole range $\lambda \in\left[\frac{1}{2}, 1\right]$.

\section{Appendix 2: Proof of Proposition 1}

To show which are the candidate equilibrium locations when $t<\bar{t}$, we investigate the sign of $\Delta r^{d}$ and $\Delta r^{c}$ in the admissible set of $\tau$, namely $\tau<\tau_{\text {trade. Two cases arise: }}$

1) if $\left(n-2 n_{h}-2 \lambda+1\right)>0 \Leftrightarrow n_{h}<\frac{n}{2}-\left(\lambda-\frac{1}{2}\right)$, then, $\Delta r^{d}>\Delta r^{c}>0$. Hence, the candidate equilibrium locations that can arise in the feasible set is only scenario (i), namely 
coagglomeration in country $H$. However, this cannot be an equilibrium location, because coagglomeration in the large country $s_{c}^{*}=s_{d}^{*}=1$ is in contradiction with the condition $n_{h}<$ $\frac{n}{2}-\left(\lambda-\frac{1}{2}\right) !$

2) if $\left(n-2 n_{h}-2 \lambda+1\right) \leq 0 \Leftrightarrow n_{h} \geq \frac{n}{2}-\left(\lambda-\frac{1}{2}\right)$, then, the candidate equilibrium locations are all four spatial configurations ${ }^{9}$. We know that for any $t \in[0 ; \bar{t}), \tau^{d}(t)>\tau^{c}(t)$. These two thresholds as well as the trade condition $\tau_{\text {trade }}(t)$ are monotonic decreasing functions of $t$. Then, to spot the location equilibria, for any $t \in[0, \bar{t})$, we shall investigate the value of the trade condition for $\bar{t}$ (knowing from Appendix 1 that for $t=0, \tau_{\text {trade }}>\tau^{d}(0)$. If the trade condition at $\bar{t}$, is higher than $\tau_{c}(\bar{t})$, then all four spatial configurations are equilibrium location for any admissible $\tau$ and $t$. First notice that at $\bar{t}$ we have

$$
\tau^{c}(\bar{t})=\tau^{d}(\bar{t})=2(2 \lambda-1) \frac{a \varepsilon_{d}-a \varepsilon_{c}-m \varepsilon_{d}}{\left(\varepsilon_{d}-\varepsilon_{c}\right)(-(n-2 \lambda-2 n \mu+1))}
$$

while the corresponding trade cost threshold is

$$
\tau_{\text {trade }}(\bar{t})=\frac{a \varepsilon_{d}-a \varepsilon_{c}-m \varepsilon_{d}}{(n+1)\left(\varepsilon_{d}-\varepsilon_{c}\right)}
$$

which are both positive.

Taking the difference $\tau_{\text {trade }}(\bar{t})-\tau^{c}(\bar{t})$, we have

$$
\tau_{\text {trade }}(\bar{t})-\tau^{c}(\bar{t})=\frac{\left(-n+2 \lambda+4 n \lambda-2 n_{h}-1\right)\left(a \varepsilon_{c}-a \varepsilon_{d}+m \varepsilon_{d}\right)}{(n+1)[-(n-2 n \mu-2 \lambda+1)]\left(\varepsilon_{d}-\varepsilon_{c}\right)}
$$

which is negatively signed (implying $\tau^{c}(\bar{t})>\tau_{\text {trade }}(\bar{t})$ ) if and only if the numerator

$$
\left(-n+2 \lambda+4 n \lambda-2 n_{h}-1\right)\left(a \varepsilon_{c}-a \varepsilon_{d}+m \varepsilon_{d}\right)<0
$$

It can be easily checked that if $\left[-\left(n-2 n_{h}-2 \lambda+1\right)\right]>0$ then $\left(-n+2 \lambda+4 n \lambda-2 n_{h}-1\right)>0$. While the second component $\left(a \varepsilon_{c}-a \varepsilon_{d}+m \varepsilon_{d}\right)$ is positive due to positivity of $\tau_{\text {trade }}(\bar{t})$. It follows that if $\tau^{c}(\bar{t})>\tau_{\text {trade }}(\bar{t})$, and for any $t \in[0 ; \bar{t}), \tau^{d}(t)>\tau^{c}(t)$. Then, in the interval $t \in[0 ; \bar{t})$, the curve $\tau_{\text {trade }}(t)$ intercepts once the curve $\tau_{d}(t)$. Call this intercept $t_{1}$. And $\tau_{\text {trade }}(t)$ intercepts once the curve $\tau_{c}(t)$. Call this second intercept $t_{2}$.

\footnotetext{
${ }^{9}$ Notice that, as we said, $\Delta r^{c}<\Delta r^{d}<0$ is never an equilibrium location because it does not satisfy the condition $n_{h} \geq \frac{n}{2}-\left(\lambda-\frac{1}{2}\right)$. By contrast, we verify that $n_{h}^{\left(0 ; s_{d}\right)}>\frac{n}{2}-\left(\lambda-\frac{1}{2}\right)$ for all positive trade condition. Given that $n_{h}^{\left(0 ; s_{d}\right)}<n_{h}^{(0 ; 1)}<n_{h}^{\left(s_{c} ; 1\right)}<n_{h}^{(1 ; 1)}$, candidate location equilibria are the four remaining spatial configurations $\left(0 ; s_{d}\right),(0 ; 1),\left(s_{c} ; 1\right)$ and $(1 ; 1)$.
} 
Let us now analyze the position of $\tau_{a}(\bar{t})$ with respect to the other threshold values. We first verify that:

$$
\tau^{c}(\bar{t})-\tau_{a}(\bar{t})=4 n(1-\mu)(2 \lambda-1) \frac{a \varepsilon_{c}-a \varepsilon_{d}+m \varepsilon_{d}}{(n+2 \lambda-1)(-n+2 \lambda+2 n \mu-1)\left(\varepsilon_{c}-\varepsilon_{d}\right)}
$$

is positive. Moreover, the difference between $\tau_{\text {trade }}(\bar{t})$ and $\tau^{a}(\bar{t})$ writes:

$$
\tau_{\text {trade }}(\bar{t})-\tau_{a}(\bar{t})=(3 n-2 \lambda-4 n \lambda+1) \frac{a \varepsilon_{c}-a \varepsilon_{d}+m \varepsilon_{d}}{(n+1)(n+2 \lambda-1)\left(\varepsilon_{c}-\varepsilon_{d}\right)}
$$

We verify that $\tau_{a}(\bar{t}) \lessgtr \tau_{\text {trade }}(\bar{t})$ when $\lambda \lessgtr(3 n+1) /(4 n+2)$. Then, the curve $\tau_{\text {trade }}(t)$ intercepts once the curve $\tau_{a}(t)$ and we call this intercept $t_{3}$. Then, $t_{3}$ lies in the interval $t \in[0 ; \bar{t})$ if $\lambda>(3 n+1) /(4 n+2)$ whereas it lies in the interval $t \in[\bar{t} ;+\infty)$ otherwise. Moreover, we check that $d \tau_{d}(t) / d t<d \tau_{c}(t) / d t<d \tau_{a}(t) / d t<0$. Therefore, we conclude that $t_{1}<t_{2}<t_{3}<\bar{t}$ when $\lambda>(3 n+1) /(4 n+2)$ whereas $t_{1}<t_{2}<\bar{t}<t_{3}$ when $\lambda<(3 n+1) /(4 n+2)$.

Consequently, for $t<t_{1}, \tau_{\text {trade }}(t)>\tau^{d}(t)$ (recall that for $t=0$, we proved in Appendix 1 that $\left.\tau_{\text {trade }}(t)>\tau^{d}(t)\right)$. Then, all four scenarios arise as equilibrium locations. If $t_{1} \leq t \leq t_{2}$, then $\tau_{d}(t)$ does not lie in the admissible set of values, implying that scenario (iv) cannot arise in equilibrium. For values of the carbon tax higher than $t_{2}$, we must distinguish between two cases. If $\lambda<(3 n+1) /(4 n+2)$, then all carbon tax values that lie in the interval $[0 ; \bar{t})$ are lower than $t_{3}$. Therefore, only $\tau_{a}(t)$ lie in the admissible set of values, implying that configurations (i) and (ii) are the only equilibrium scenarii. If, however, $\lambda>(3 n+1) /(4 n+2)$, the equilibrium configurations depend on wether the carbon tax is higher or lower than $t_{3}$. Configurations (i) and (ii) are the only equilibrium scenarii when $t_{2} \leq t \leq t_{3}$, whereas only configuration (i) arises as an equilibrium scenario when $t>t_{3}$.

\section{Appendix 3: Proof of Proposition 4}

To show which are the candidate equilibrium locations $t>\bar{t}$, we investigate the sign of $\Delta r^{d}$ and $\Delta r^{c}$ for all $\tau<\tau_{\text {trade }}^{\prime}$

Assume that $n-2 n_{h}-2 \lambda+1>0$. Then, in the absence of carbon tax, both $\Delta r^{c}$ and $\Delta r^{d}$ are positive so that coagglomeration in the large country $(1,1)$ should be an equilibrium and $n_{h}$ should be equal to $n$. However, this would imply $n-2 n_{h}-2 \lambda+1<0$ and contradicts our first assumption. The only candidate location equilibrium such that $n_{h} \geq \frac{n}{2}-\left(\lambda-\frac{1}{2}\right)$ are the four spatial configurations $(1 ; 1),\left(1 ; s^{d}\right),(1 ; 0)$ and $\left(s^{c}, 0\right)$. 
Then, we investigate whether these candidate equilibrium locations are compatible with the trade condition $\tau<\tau_{\text {trade }}^{\prime}$. To do so, we have to rank thresholds $\tau_{a}^{\prime}, \tau_{c}^{\prime}, \tau_{d}^{\prime}$ and $\tau_{\text {trade }}^{\prime}$ over the interval $\left(\bar{t} ; t_{\max }\right)$. Recalling that these thresholds are all monotonic decreasing functions of $t$, we only need this ranking at the two extreme values of the carbon tax, that is $\bar{t}$ and $t_{\max }$.

Let us first compare $\tau_{a}^{\prime}(\bar{t}), \tau_{c}^{\prime}(\bar{t})$ and $\tau_{d}^{\prime}(\bar{t})$ with $\tau_{\text {trade }}^{\prime}$. First of all, recall that $\tau_{\text {trade }}^{\prime}(\bar{t})=$ $\tau_{\text {trade }}(\bar{t})$. The remaining threshold values write:

$$
\tau_{c}^{\prime}(\bar{t})=\tau_{d}^{\prime}(\bar{t})=2(2 \lambda-1) \frac{a \varepsilon_{d}-a \varepsilon_{c}-m \varepsilon_{d}}{\left(\varepsilon_{d}-\varepsilon_{c}\right)(n+2 \lambda-2 n \mu-1)}
$$

and

$$
\tau_{a}^{\prime}(\bar{t})=2(2 \lambda-1) \frac{a \varepsilon_{c}-a \varepsilon_{d}+m \varepsilon_{d}}{\left(\varepsilon_{c}-\varepsilon_{d}\right)(n+2 \lambda-1)}
$$

Given the positivity of $\tau_{\text {trade }}^{\prime}(\bar{t})$, both expressions are positive and $\tau_{a}^{\prime}(\bar{t})<\tau_{c, d}^{\prime}(\bar{t})=\tau_{d}^{\prime}(\bar{t})$.

We now take the difference between $\tau_{\text {trade }}^{\prime}(\bar{t})$ and the above thresholds. We obtain:

$$
\tau_{\text {trade }}^{\prime}(\bar{t})-\tau_{d}^{\prime}(\bar{t})=\left(a \varepsilon_{c}-a \varepsilon_{d}+m \varepsilon_{d}\right) \frac{(-3 n+2 \lambda+4 n \lambda-1+2 n \mu)}{\left(\varepsilon_{d}-\varepsilon_{c}\right)(n+1)(n+2 \lambda-2 n \mu-1)}
$$

and

$$
\tau_{\text {trade }}^{\prime}(\bar{t})-\tau_{a}^{\prime}(\bar{t})=(-3 n+2 \lambda+4 n \lambda-1) \frac{a \varepsilon_{c}-a \varepsilon_{d}+m \varepsilon_{d}}{(n+1)(n+2 \lambda-1)\left(\varepsilon_{d}-\varepsilon_{c}\right)}
$$

The first expression is negatively signed due to positivity of $\tau_{\text {trade }}^{\prime}(\bar{t})$. By contrast, the sign of the second expression depends on the asymmetry of market size. Specifically, we verify that $\tau_{\text {trade }}^{\prime}(\bar{t}) \lessgtr \tau_{a}^{\prime}(\bar{t})$ when $\lambda \gtrless(3 n+1) /(4 n+2)$. Thus, the ranking of threshold values with respect to the trade condition is $\tau_{a}^{\prime}(\bar{t})<\tau_{\text {trade }}^{\prime}(\bar{t})<\tau_{d}^{\prime}(\bar{t})<\tau_{c}^{\prime}(\bar{t})$ for all $\lambda<(3 n+1) /(4 n+2)$ and $\tau_{\text {trade }}^{\prime}(\bar{t})<\tau_{a}^{\prime}(\bar{t})<\tau_{d}^{\prime}(\bar{t})<\tau_{c}^{\prime}(\bar{t})$ for all $\lambda>(3 n+1) /(4 n+2)$.

To complete the analysis, we now compare these thresholds with the trade condition when the carbon tax takes the maximum value $t_{\max }$. We verify that:

$$
\tau_{\text {trade }}^{\prime}\left(t_{\max }\right)-\tau_{a}^{\prime}\left(t_{\max }\right)=2 n \mu(2 \lambda-1) \frac{a \varepsilon_{c}-a \varepsilon_{d}+m \varepsilon_{d}}{(n+2 \lambda-1)\left(\varepsilon_{d}+n \varepsilon_{d}-n \varepsilon_{c}\right)}
$$

is negative due to positivity of $\tau_{\text {trade }}^{\prime}(\bar{t})$, so that $\tau_{\text {trade }}^{\prime}\left(t_{\max }\right)<\tau_{a}^{\prime}\left(t_{\max }\right)<\tau_{d}^{\prime}\left(t_{\max }\right)<\tau_{c}^{\prime}\left(t_{\max }\right)$. Therefore at the maximum value of the carbon tax, the only spatial equilibrium compatible with the trade condition is coagglomeration in the larger country $(1 ; 1)$.

To summarize, $\tau_{\text {trade }}^{\prime}(t)$ is lower than $\tau_{d}^{\prime}(t)$ and $\tau_{c}^{\prime}(t)$ for all $t \in\left(\bar{t} ; t_{\text {max }}\right)$ whereas $\tau_{\text {trade }}^{\prime}(t)$ can be higher or lower than $\tau_{a}^{\prime}(t)$ when the size asymmetry is not too large. As all thresholds value are monotonic decreasing functions with respect to the carbon tax, this implies that the 
curve $\tau_{\text {trade }}^{\prime}(t)$ intercepts once the curve $\tau_{a}^{\prime}(t)$ when $\lambda<(3 n+1) /(4 n+2)$. Let us call $t_{4}$ this intercept that lies in the interval $t \in\left(\bar{t} ; t_{\max }\right)$. Then, we verify that $\tau_{\text {trade }}^{\prime}(t) \lessgtr \tau_{a}^{\prime}(t)$ when $t \gtrless t_{4}$.

We can now define which candidate location equilibrium are compatible with the trade condition over the interval $\left(\bar{t}, t_{\max }\right)$. If $\lambda>(3 n+1) /(4 n+2), \tau_{\text {trade }}^{\prime}(t)<\tau_{a}^{\prime}(t)<\tau_{d}^{\prime}(t)<$ $\tau_{c}^{\prime}(t)$ for all $t \in\left(\bar{t}, t_{\max }\right)$, so that $(1,1)$ is the only location equilibrium compatible with the trade condition. If, however, $\lambda<(3 n+1) /(4 n+2)$, then spatial configurations $(1 ; 1)$ and $\left(1 ; s_{d}\right)$ can arise in equilibrium when $t \leq t_{4}$ whereas coagglomeration $(1 ; 1)$ is the only spatial configuration equilibrium when $t>t_{4}$.

\section{Dirty firms have the highest marginal cost}

In this section, we assume that the carbon tax reaches such a high level that the clean firms now enjoy the lowest (post-tax) marginal cost, that is $t>\bar{t}$. Then, we verify that $\tau_{\text {trade }}^{\prime}<\tau_{\text {trade }}$, yielding the following simplified trade condition:

$$
\tau<\tau_{\text {trade }}^{\prime}(t)=\frac{a+m n-t\left(n \varepsilon_{d}-n \varepsilon_{c}+\varepsilon_{d}\right)}{n+1}
$$

with $t<\frac{a+m n}{\varepsilon_{d}+n\left(\varepsilon_{d}-\varepsilon_{c}\right)}=t_{\max }^{\prime}$ so that $0<\tau_{\text {trade }}^{\prime}(t)$.

\subsection{Long run spatial equilibrium}

The inequality $t>\bar{t}$ implies that the spatial difference in return to capital between the large and the small country is now higher for clean firms (that is, $\Delta r^{c}>\Delta r^{d}$ ). In other terms, because the carbon tax is high enough, dirty firms have now lower incentives to locate in the large country than clean ones.

As a consequence, the equilibrium location of firms cannot involve an interior configuration for each type of firms, that is $\Delta r^{c}=\Delta r^{d}=0$. Moreover, we check that expressions $(a-$ $\left.(n+1)\left(m+t \varepsilon_{c}\right)+n \omega\right)$ and $\left(a-(n+1) t \varepsilon_{d}+n \omega\right)$ entering $\Delta r^{c}$ and $\Delta r^{d}$ are positive for all $\tau<\tau_{\text {trade }}^{\prime}(t)$. Thus, the complete coagglomeration of firms in the small country cannot arise because $\Delta r^{c}\left(n_{h}=0\right)>0$ and $\Delta r^{d}\left(n_{h}=0\right)>0$.

Finally, we show in Appendix 3 that $\left(n-2 n_{h}-2 \lambda+1\right)<0$ so that $\Delta r^{c}$ and $\Delta r^{d}$ are decreasing in $\tau$. Thus, we can define threshold values of trade cost that determine the switch 
from a spatial configuration to another. For that purpose, let us define :

$$
\begin{aligned}
\tau_{a}^{\prime}(t) & =2(2 \lambda-1) \frac{a+m n(1-\mu)-\left(\varepsilon_{d}+n\left(\varepsilon_{d}-\varepsilon_{c}\right)(1-\mu)\right) t}{n+2 \lambda-1}, \\
\tau_{c}^{\prime}(t) & =2(2 \lambda-1) \frac{a-m(n \mu+1)-t\left(\varepsilon_{c}+n \mu\left(\varepsilon_{c}-\varepsilon_{d}\right)\right)}{n+2 \lambda-2 n \mu-1}, \\
\tau_{d}^{\prime}(t) & =2(2 \lambda-1) \frac{a+m n(1-\mu)-\left(\varepsilon_{d}+n\left(\varepsilon_{d}-\varepsilon_{c}\right)(1-\mu)\right) t}{n+2 \lambda-2 n \mu-1},
\end{aligned}
$$

where $\tau_{a}^{\prime}(t)$ and $\tau_{d}^{\prime}(t)$ are obtained by requiring $\Delta r^{d}=0$ at spatial configurations $\left(s_{c}=1 ; s_{d}=1\right)$ and $\left(s_{c}=1 ; s_{d}=0\right)$, respectively, whereas $\tau_{c}^{\prime}(t)$ is obtained by requiring $\Delta r^{c}=0$ at spatial configurations $\left(s_{c}=1 ; s_{d}=0\right)$. We can easily check that $\tau_{c}^{\prime}>\tau_{d}^{\prime}>\tau_{a}^{\prime}>0$.

In order to define all possible spatial configurations, let us consider:

$$
\hat{s}_{c}^{t}=\tilde{s}_{c}^{t}+\frac{\mu}{1-\mu} \text { and } \hat{s}_{d}^{t}=\tilde{s}_{d}^{t}-\frac{1-\mu}{\mu} .
$$

which confirms that imposing a carbon tax higher than the threshold $\bar{t}$ erodes the attractiveness of the large country for dirty firms.

Then, the possible spatial configurations $\left(\hat{s}_{c}^{t}, \hat{s}_{d}^{t}\right)$ are as follows:

(i) Agglomeration of dirty firms in the smaller country and partial selection of clean firms in the larger country $\left(\hat{s}_{c}^{t} ; 0\right)$ when $\tau>\tau_{c}^{\prime}(t)$;

(ii) Perfect selection of clean firms in the larger country and dirty firms in the smaller country $(1,0)$ when $\tau_{c}^{\prime}(t) \geqslant \tau>\tau_{d}^{\prime}(t)$;

(iii) Partial selection of dirty firms and agglomeration of clean ones in the larger country $\left(1, \hat{s}_{d}^{t}\right)$ when $\tau_{d}^{\prime}(t) \geqslant \tau>\tau_{a}^{\prime}(t)$

(iv) Co-agglomeration in the larger country $(1,1)$ when $\tau \leqslant \tau_{a}^{\prime}(t)$.

Clearly, the decline in trade cost induces the relocation of firms from the smaller to the larger country. The mechanisms driving this progressive agglomeration to the larger country are similar as when the carbon tax is lower than $\bar{t}$ : trade integration weakens the dispersion force (due to competition) whereas it strengthens the agglomeration force (due to the market size advantage of country $H$ ). The only difference is that as clean firms now enjoy the lowest net marginal cost, they are the first ones to relocate to the larger country when trade costs fall below $\tau_{c}^{\prime}(t)$. By contrast, dirty firms stay longer in the small market in order to protect themselves from competition induced by clean firms, and they start relocating to the large country only when trade cost fall below $\tau_{d}^{\prime}(t)$.

Then, we can determine whether or not each one of these spatial configuration can arise under the trade condition $\tau<\tau_{\text {trade }}^{\prime}$. We obtain the following result: 
Proposition 4 Given $t \in\left(\bar{t} ; t_{\max }\right)$ and $\tau \in\left[0 ; \tau_{\text {trade }}^{\prime}\right)$, there exists a threshold value of the carbon tax $t_{4}^{\prime}$ such that:

(a) if $t \leq t_{4}$ and $\lambda<(3 n+1) /(4 n+2)$, then spatial configurations $(1,1)$ and $\left(1, \hat{s}_{d}^{t}\right)$ are equilibria locations

(b) if $t>t_{4}$ and $\lambda<(3 n+1) /(4 n+2)$, or if $\lambda \geq(3 n+1) /(4 n+2)$, co-agglomeration in the larger country $(1,1)$ is the only equilibrium location.

\section{Proof. See Appendix 3.}

When the carbon tax is higher than $\bar{t}$, only the most concentrated spatial configurations $(1,1)$ and $\left(1, \hat{s}_{d}^{t}\right)$ can arise in equilibrium. This is not surprising as we show in section 4 that the rise in the carbon tax (from 0 to $\bar{t}$ ) triggers the exclusion of the most dispersed spatial configurations.

The intuition for this result is the same as in section 4, and comes from the no-trade effect. The carbon tax renders the trade condition even more binding $\left(d \tau_{\text {trade }}^{\prime} / d t<d \tau_{\text {trade }} / d t<\right.$ 0 ) so that threshold values $\tau_{c}^{\prime}$ and $\tau_{d}^{\prime}$ are always higher than $\tau_{\text {trade }}^{\prime}$ and the most dispersed spatial configurations are not compatible with the trade condition anymore. The only spatial configurations ensuring that trade is profitable for firms are $(1,1)$ and $\left(1, \hat{s}_{d}^{t}\right)$. Specifically, coagglomeration $(1,1)$ is always compatible with the trade condition whereas the configuration $\left(1, \hat{s}_{d}^{t}\right)$ can arise if and only if $t<t_{4}$ and $\lambda<(3 n+1) /(4 n+2)$ (so that $\left.\tau_{a}^{\prime}<\tau_{\text {trade }}^{\prime}\right)$.

Figure 4 illustrates Proposition 4 when $\lambda<(3 n+1) /(4 n+2)$ (left panel) and $\lambda>$ $(3 n+1) /(4 n+2)$ (right panel), respectively.

\subsection{Pollution}

Let us now analyze how global pollution evolves as the economy moves from spatial configuration $(1 ; 1)$ to $\left(1 ; \hat{s}_{d}^{t}\right)$. The level of emissions when all firms are agglomerated in the larger country being decreasing with the carbon tax (with $d \boldsymbol{E}^{t}(1,1) / d t=\Lambda>0$ ), global emissions are lower when $t>\bar{t}$ for all $\tau<\tau_{a}^{\prime}(t)$. Regarding the spatial configuration $\left(1 ; \hat{s}_{d}^{t}\right)$, the level of global emissions can be written as follows

$$
\boldsymbol{E}\left(1 ; \hat{s}_{d}^{t}\right) \equiv \boldsymbol{E}\left(\tilde{s}_{c}^{t}, 1\right)+\frac{l}{\beta}(2 \lambda-1)\left(\frac{1}{2} \Gamma-\Omega t\right)
$$



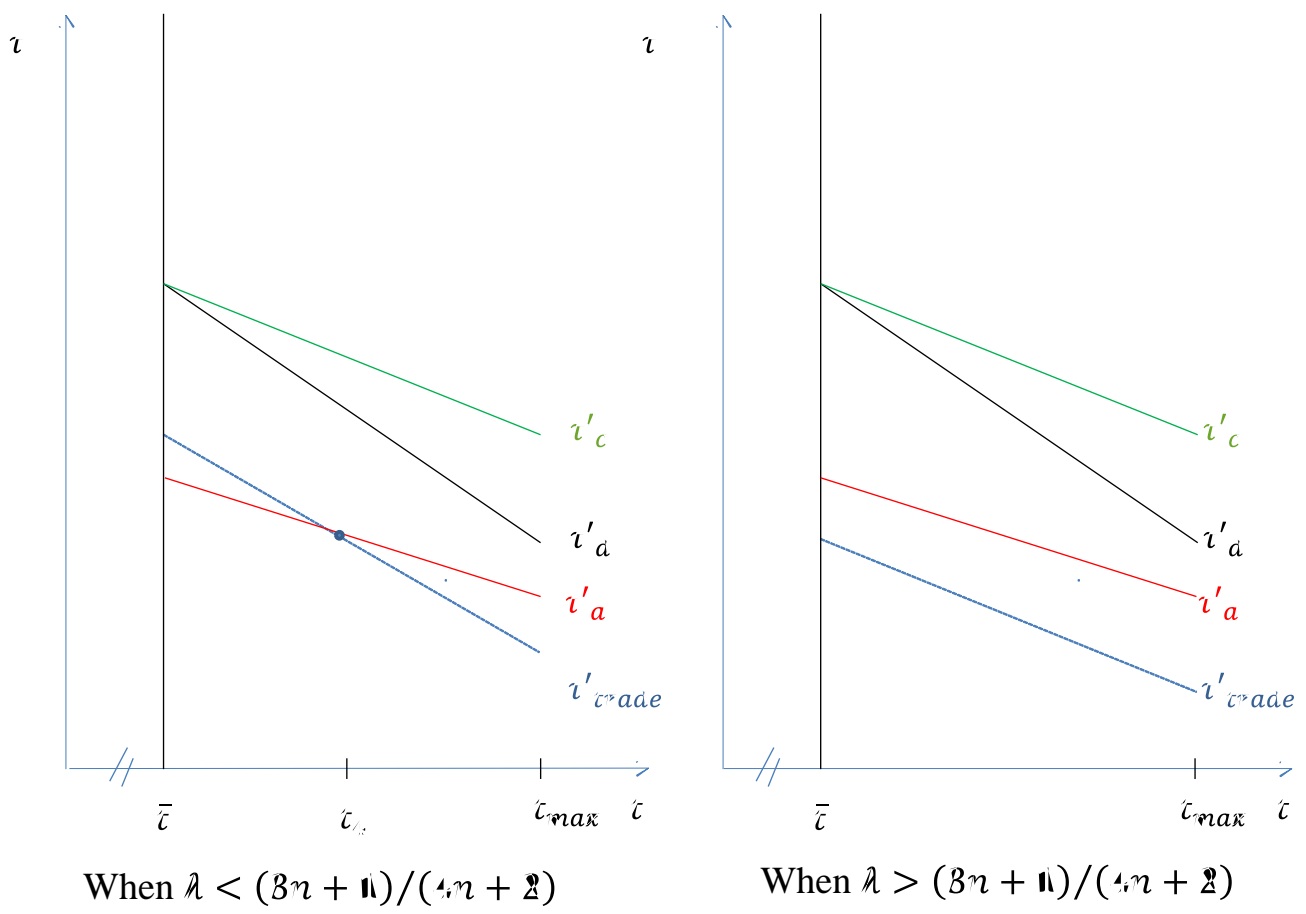

Figure 4: Location equilibria for all $t>\bar{t}$

with

$$
\begin{aligned}
\Omega & =(2 \lambda-1)\left(\varepsilon_{d}-\varepsilon_{c}\right)\left[\varepsilon_{c}+\varepsilon_{d}+n\left(\varepsilon_{d}-\varepsilon_{c}\right)(1-2 \mu)\right]>0 \\
\Gamma & =2(2 \lambda-1)\left[\left(\varepsilon_{d}-\varepsilon_{c}\right)(a+m n-2 m n \mu)+m \varepsilon_{c}\right]-\tau(n+2 \lambda-1)\left(\varepsilon_{d}-\varepsilon_{c}\right)
\end{aligned}
$$

and

$$
\boldsymbol{E}(1,1) \gtrless \boldsymbol{E}\left(1, s_{d}^{\prime}\right) \text { for all } \tau \gtrless \tau_{a}^{\prime}(t)
$$

Therefore, trade integration is still detrimental to the environment when $t>\bar{t}$. Moreover, it is readily verified that $\tau_{a}(t)>\tau_{a}^{\prime}(t)$ and $d \boldsymbol{E}\left(\tilde{s}_{c}^{t}, 1\right) / d \tau>d \boldsymbol{E}\left(1 ; \hat{s}_{d}^{t}\right) / d \tau$. These properties allow us to illustrate the pollution paths with respect to the level of trade cost under the three main cases: absence of taxation, $t<\bar{t}$ and $t>\bar{t}$. Precisely, the evolution of pollution when $t<\bar{t}$ is depicted by making the assumption that $\lambda<(3 n+1) /(4 n+2)$ and $t_{2}<t$ while $\lambda<(3 n+1) /(4 n+2)$ and $t<t_{4}$ are assumed to be checked when $t>\bar{t}$. 


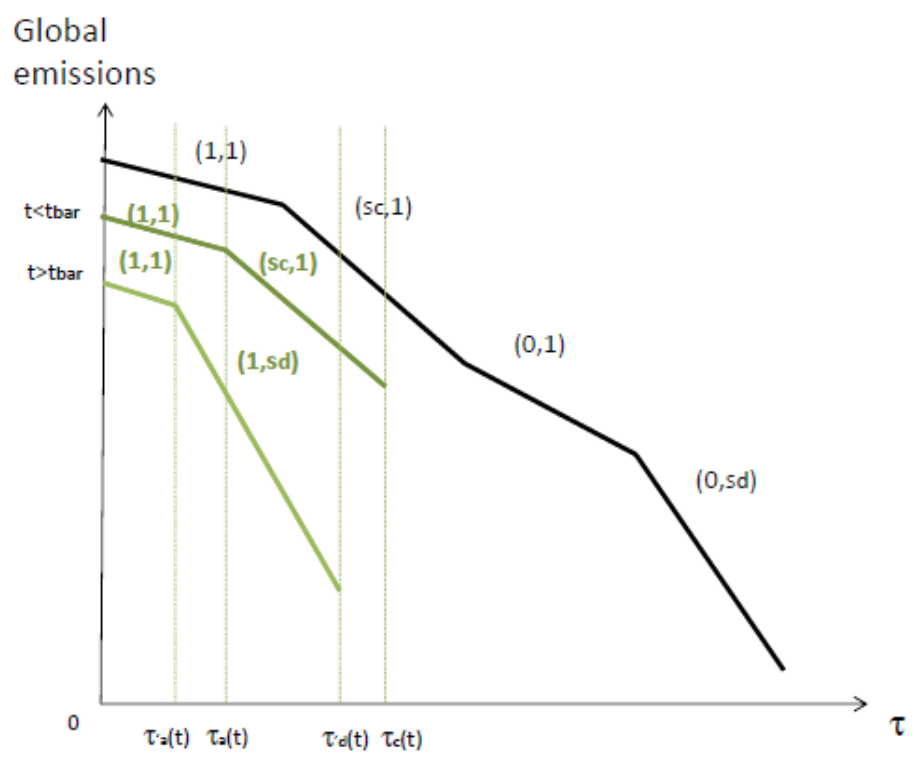

Unsurprisingly, the above Figure illustrates that a carbon tax policy is environmentally more efficient for a high level of taxation. The first reason is that the Pigouvian effect is proportional to the level of taxation. The second one lies on the fact that the carbon tax may be high enough to make the large country an unprofitable location choice for all dirty firms. Indeed, at a level of trade cost within the range $\left(\tau_{a}^{\prime}(t), \tau_{d}^{\prime}(t)\right)$ and after taxation, the spatial configurations $(1,1)$ and $\left(s_{c}, 1\right)$ cannot be equilibria. As a consequence, some dirty firms relocate in the small country with a strong and positive environmental outcome.

As said before, trade liberalization is at the origin of more pollution whatever the location equilibrium of the economy. However, observe that when the two types of firms are not fully agglomerated in the large country, the detrimental effect of trade liberalization on pollution is stronger when the level of taxation is high and above $\bar{t}$. Indeed, in this case, trade liberalization acts as an agglomeration force of the most polluting firms in the large country. In contrast, the environmental consequences are less important when $t<\bar{t}$ because these are the less polluting firms that relocate toward this country. 


\section{References}

[1] Ahmad N., and A. Wyckoff (2003). Carbon Dioxide Emissions Embodied in International Trade of Goods. Organisation for Economic Co-Operation and Development, Paris.

[2] Antweiler, W., Copeland, B., and Taylor, S. (2001). Is Free Trade Good for the Environment? American Economic Review, 91, 877-908.

[3] Copeland, B., and Talyor, S. (1994). North-South Trade and the Environment. Quarterly Journal of Economics, 109, 755-87

[4] Ederington, J.; Levinson A.; and J. Miniet (2005). Footloose and Pollution-Free. Review of Economics and Statistics 87; pages 92-99.

[5] Eskeland, G. S. and A. E. Harrison (2003). Moving to greener pastures? Multinationals and the pollution haven hypothesis. Journal of Development Economics, vol. 70(1), pages $1-23$.

[6] Exbrayat N., Gaigné C. and Riou S. (2013). Taxe carbone globale, effet taille de marché et mobilité des firmes. Revue économique, Presses de Sciences-Po, vol. 64(2), pages 265-278.

[7] Grossman, G. M. and A. B. Krueger (1993). Environmental Impacts of a North American Free Trade Agreement. In Peter M. Garber, ed., The U.S.-Mexico free trade agreement. Cambridge, MA: MIT Press, 1993, pp. 13-56.

[8] Hoel, M. (1997). Environmental Policy with Endogenous Plant Locations. Scandinavian Journal of Economics, 99, 241-59.

[9] IPCC WGIII AR5. Climate Change 2014: Mitigation of Climate Change. Summary for Policymakers.

[10] Jeppesen, T., List, J., and H. FolmerH. (2002). Environmental Regulations and New Plant Location Decisions: Evidence from a Meta-analysis. Journal of Regional Science, 42, 1949.

[11] Levinson A. and S. Taylor (2008). Unmasking the pollution havin effect. International Economic Review, 46(1), 223-254. 
[12] Lin B. and C. Sun (2010). Evaluating carbon dioxide emissions in international trade of China. Energy Policy 38, pp.613-621.

[13] Mankiw, G. (2007). One Answer to Global Warming: A New Ta. N-Y. Times, October 16 th.

[14] Markusen J., Morey E. and N. Olewiler (1993). Environmental Policy when Market Structure and Plant Locations are Endogenous. Journal of Environmental Economics and Management, 24, 68-86.

[15] Markusen J., Morey E. and N. Olewiler (1995). Competition in Regional Environmental Policies when Plant Locations are Endogenous. Journal of Public Economics, 56, 55-77.

[16] Motta M. and J-F. Thisse (1994). Does Environmental Dumping Lead to Delocation ? European Economic Review, 38, 563-76.

[17] Nordhaus W. D., (2006). After Kyoto: Alternative Mechanisms to Control Global Warming. American Economic Review, vol. 96, 31-34.

[18] Okubo T., Picard P and J-F Thisse (2010). The spatial selection of heterogeneous firms. Journal of International Economics, Elsevier, vol. 82(2), pages 230-237.

[19] Peters G.P. (2008). From production-based to consumption-based national emission inventories, Ecological Economics $6513-23$ pp.

[20] Peters G.P., and E.G. Hertwich (2008). CO2 Embodied in International Trade with Implications for Global Climate Policy, Environmental Science \& Technology 42, 1401-1407 pp.

[21] Pflüger M. (2001). Ecological Dumping under Monopolistic Competition. Scandinavian Journal of Economics, 103(4), 689-706.

[22] Rauscher, M. (1995). Environmental Regulation and the Location of Polluting Industries. International Tax and Public Finance, 2, 229-44.

[23] Stigltiz (2006). A New Agenda for Global Warming. In The Economists' Voice: Top Economists Take on Today's Problems, J.E. Stigliz, A. Edlin, and J.B. DeLong, eds., Columbia University Press: New York, pp. 22-27 
[24] Sturm, D. (2003). Trade and the Environment: A Survey of the Literature. In Laura Marsiliani, Michael Rauscher and Cees Withagen (eds.), Environmental Policy in an International Perspective, Kluwer Academic Publishers, 119-149.

[25] Weber C.L., G.P. Peters, D. Guan, and K. Hubacek (2008). The contribution of Chinese exports to climate change. Energy Policy 36 3572-3577 pp.

[26] Zeng D. and L. Zhao (2009). Pollution havens and industrial agglomeration. Journal of Environmental Economics and Management, 58, 141-153. 